\title{
LEVANTAMENTO E FENOLOGIA DE COLEÓPTEROS E HEMIPTEROS ASSOCIADOS AO CACAUEIRO NO PARÁ
}

\author{
JOÃO DE JESUS DA SILVA GARCIA
}

Orientador: Dr. Sinval Silveira Neto

Disserłação apresentada à Escola Superior de Agricultura "Luiz de Queiroz", da Universidade de São Paulo, para obtenção do título de Mestre em Entomologia.

$P \mid R A C I C A B A$

Estado de São Paulo - Brasil

Janeiro, 1979 
a meu pai (in memoriam) e
a minha mãe, pelo exemplo e
educação que me deram,

MEU AGRADECIMENTO

a minha esposa Wania e a

aos meus filhos Adexandre, Erick

e Itatiene, pela compreensão

e incentivos. 
0 autor expressa seus agradecimentos a todos que,d reta ou indiretamente, contribuiram para a realização deste trabalho, especialmente:

A Comissão Executiva do Plano da Lavoura Cacaueira (CEPLAC), pela oportunidade de aperfeiçoamento concedida;

Ao Departamento Especial da Amazônia (DEPEA) da CEPLAC, na pessoa de seu Diretor Frederico $\bar{A}$ lvares Afonso,pelo apoio e incentivo;

Ao Prof. Sinval Silveira Neto, Professor Adjunto do Departamento de Entomologia da Escola Superior de Agricultura "Luiz de Queiroz", pela eficiente orientação, amizade e estímulos recebidos;

Aos Demais Professores do Departamento de Entomologia da E. S. A. "Luiz de Queiroz"-USP, na pessoa de seu Chefe Prof. Domingos Gallo, pelos ensinamentos recebidos;

Aos Drs Ubirajara R. Martins, do Museu de Zoologia da USP; Sërgio Vanin, do Departamento de Zoologia da USP; Jocëlia Grazia, do Departamento de Zoologia da UNICAMP e José Cândido de Carvalho, do Museu Nacional do Rio de Janeiro, pela colaboração prestada na identificação dos insetos;

Ao Dr. Décio Barbin, Professor Livre Docente do Departamento de Matemática e Estatística da Escola Superior de Agricul tura "Luiz de Queiroz", pela orientação na anälise estatística; 
Ao Dr. Evoneo Berti Filho, Assistente Doutor do Departamento de Entomologia da E. S. A. "Luiz de Queiroz", pela versão do resumo em inglês;

Aos Colegas da CEPLAC, Antonio Carlos de Barros Mendes e Ruth Maria Cordeiro Scerne, pela colaboração prestada no levan tamento dos insetos e dados fenolögicos;

A EMBRAPA-CEPATU, em Belèm (PA) e a Colōnia Agrícola da JAMIC, em Tomé-Açü (PA), pelo fornecimento dos dados meteorolögicos;

Ao Eng:-Agr: Murilo Fazolin, bolsista do Departamento de Entomologia da ESALQ/USP, pela ajuda na separação e monta gem dos insetos.

Aos Demais Colegas de Curso, pela amizade e apoio recebidos. 


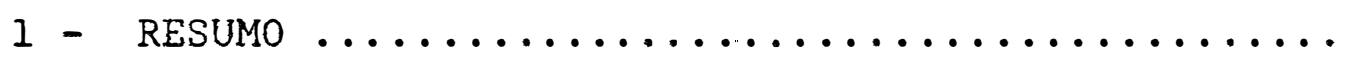

$2-$ INTRODUÇÃO $\ldots \ldots \ldots \ldots \ldots \ldots \ldots \ldots \ldots \ldots \ldots \ldots \ldots \ldots \ldots \ldots \ldots$

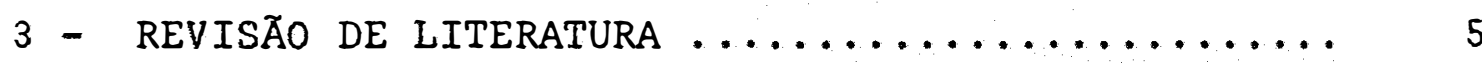

3.1 - Insetos pragas associados a cacauicul-

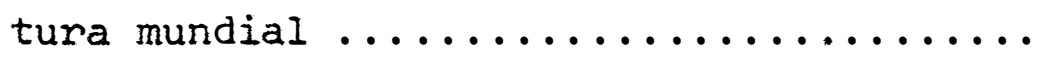

3.2 - Insetos pragas associados a cacauicultura brasileira ................ 10

3.3 - Entomofauna do cacaueiro na Amazônia .... 13

4 - MATERIAIS E MÉTODOS ............................ 15

4.1 - Características das äreas experimentais. 15

4.2 - Fatores climäticos .............. 16

4.3 - Estudo fenolögico do cacaueiro ........ 16

4.3.1 - Lançamento de folhas novas ....... 17

4.3.2 - Contagem do número de frutos ma duros ................... 17

4.3.3 - Contagem do número de frutos pecos. 17

4.4 - Levantamento dos insetos ............. 18

4.5 - Indice de diversidade ............ 18

4.6 - Constância das espëcies .............. 19

4.7 - Frequência das espécies ............. 19

4.8 - Quociente de similaridade ........... 20 
5 - RESUltados E DISCUSSÃO ................... 22

5.1 - Levantamento das espécies e indices faunisticos .................. 22

5.2 - Flutuação $\ldots \ldots \ldots \ldots \ldots \ldots \ldots \ldots \ldots \ldots \ldots$

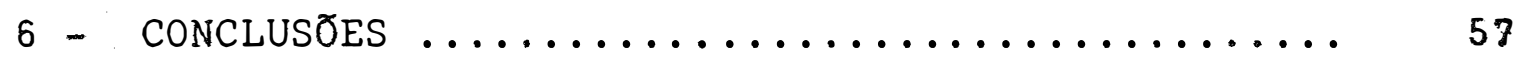

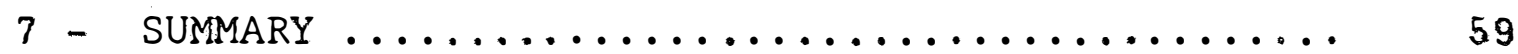

8 - LITERATURA CITADA ................... 61 
1 - RESUMO

No presente trabalho, procurou-se identificar os principais insetos das ordens Coleoptera e Hemiptera associa dos ao cacaueiro no Estado do Pará, estudar os indices faunísticos e correlacionar as curvas de população das espécies constantes, com os fatores meteorológicos e fenológicos do ca caueiro.

Para isto, foram realizados levantamentos mensais nas Regiões Bragantina e Guajarina, através de choques com B.H.C. $12 \%$, no periodo compreendido entre janeiro de 1977 e julho de 1978, chegando-se às seguintes conclusöes:

$\mathrm{Na}$ região Bragantina foram coletados 840 individuos distribuidos entre 8 famílias e 46 espécies, enquanto que na 
Região Guajarina foram coletados 695 individuos distribuidos entre 6 famỉias e 36 espécies.

Das espécies da Região Bragantina, 3 são constantes, 4 acessórias e 39 acidentais; enquanto que, das espécies da Região Guajarina, 2 são constantes, 3 acessörias e 31 acidentais.

Antiteuchus sepulcralis (Fabr., 1803) (Hemiptera Pentatomidae) é a espécie mais frequente na Região Bragantina e Ephyraea sp. (Coleoptera - Chrysomelidae) é a espécie mais frequente na Região Guajarina.

0 quociente de similaridade entre as duas regiões é de $58,5 \%$.

No estudo da flutuação populacional das espécies constantes, não hä correlação significativa com os fatores climáticos e fenológicos do cacaueiro. 
0 consumo mundial de cacau, com uma taxa de crescimento da ordem de $3,5 \%$ ao ano, apresenta um dos niveis mais altos entre os produtos agrícolas tropicais. Segundo previsões da Organização para Alimentação e Agricultura das Nações Unidas (F.A.0.), a demanda deverá alcançar em 1985, cerca de 2.400 toneladas de cacau. Para O Brasil manter a sua cota de participação entre os países produtores é necessário que dobre a sua produção atual, considerando que os outros países, paralelamente também participem com o mesmo crescimento.

A produção nacional, concentra-se atualmente quase que em sua totalidade do Estado da Bahia com $94,5 \%$, cabendo a Região Amazônica, uma participação de apenas $2,4 \%$. Entre- 
tanto, é na Amazônia que reside a maior alternativa para a ex pansão da cacauicultura brasileira, com base na disponibilidą de das imensas áreas apropriadas para essa cultura (SILVA et alii, 1976).

Assim, os polos cacaueiros da Amazônia, já preconi zados por ALVARES-AFONSO (1975), tomaram novo impulso a partir do reconhecimento potencial da área. Milhões de cacaueiros foram implantados em substituição às florestas primitivas tropicais ümidas. Como consequência lógica, ocorreu a quebra do equilíbrio das populações que constituiam a comunidade biótica daquelas áreas, proporcionando assim, para algumas e pécies de insetos, verdadeira explosão populacional. Hoje, essas espécies, em determinadas condições favoráreis, alcan çam picos populacionais superiores aos níveis de dano econômi co, constituindo-se assim, como verdadeiras pragas, ameaçando o sucesso do programa da região.

0 objetivo deste estudo foi portanto, identificar os principais insetos associados ao cacaueiro no Estado do Pa rá, estudar os indices faunisticos e estabelecer a correla ção entre as curvas de população de cada uma dessas espécies, com os fatores climáticos e fenológicos do cacaueiro, servindo assim, como subsidios para futuros trabalhos sobre avaliação de dano econômico e controle das espécies pragas de impor tância na ärea. 
3.1 - Insetos Pragas Associados a Cacauicultura Mundial.

Um dos primeiros trabalhos sobre flutuação de pragas de cacau foi o de URICH (1911) em Trinidad, observando a população de Heliothrips rủorocinctus Giard, em relação a outras plantas hospedeiras e em função das estações do ano. 0 autor, observou que nas estações chuvosas o inseto causava sérios estragos em folhas e frutos do cacaueiro e durante o período seco ou bastante seco, migrava para hospedeiros inter mediários como: cajueiro (Anacardium occidentale), goiabeira (Psidium guajava), mangueira (Mangifera indica) e roseira (Rosa sp.). Observou ainda que durante as estações úmidas 
os insetos davam preferência aos ramos terminais da copa da planta, migrando na estação seca para as partes mais baixas pröximas ao solo, atacando frutos e chupões (ramos ortotrópi cos) no tronco do cacaueiro.

Por outro lado, REYNE (1921), constatou que a maior abundância desta praga em cacaueiros do suriname, ocorre na estação seca (agosto e novembro), permanecendo em equilíbrio até o fim da pequena estação seca (fevereiro e março), alcançando finalmente a fase de crescimento negativo na grande estação chuvosa que vai de abril a julho. Não observou correla ção positiva entre a população da praga e a época de maior ocorrência de folhas novas no cacaueiro. CALLAN (1943), também observou em Trinidad que esta praga alcança maior pico po pulacional quando a estação chuvosa chega ao fim, havendo um pico subsidiārio de menor grandeza no fim da estação seca.

FENNAH (1954), contribuiu com resultados bastante e lucidativos em relação a abundância do tripes, correlacionando-a com o clima, constituição genética do hospedeiro, cresci mento, brotação de folhas e produção do cacaueiro. De acordo com o seu trabalho, o crescimento da população de tripes é de terminado pela disponibilidade de folhas em condições favoráveis para a alimentação o que ocorre com o avanço da estação chuvosa.

Em Ghana, os mirideos Sahlbergella singularis Hagl. e Distantielza theobromae (Dist.) foram objetos de estudos 
realizados por WILLIAMS (1954) que, observando os fatores que influenciavam o ciclo anual dessas pragas, pode determinar os períodos de infestação mäxima e mínima e assim fornecer sub sídios para o controle químico das mesmas. TEYLOR (1955) ten do continuado com o levantamento dos dados, encontrou uma cor relação negativa, estatisticamente significativa entre a estí mativa da população mensal de ambas as espécies e a média diá ria do déficit de saturação do ar, registrado dois meses antes. Os estudos similares realizados por LAVABRE et ali $i$ (1962 e 1963), com os mirideos do cacaueiro na Costa do Marfin, permitiram estabelecer metas de controle com o uso de in seticidas, de acordo com o clima e as condições de cultivo das diversas regiões do país.

MORALES et alii (1963) estudaram e determinaram as flutuações das populações de Monalonion spp. , Amastris obtegens Fabr., Clastoptera globosa Fabr., tripes e afideos. 0 objetivo foi encontrar as relações entre as flutuações destas pragas com as variações climáticas e, com isso, estabelecerem melhores métodos de controle.

Na Nigéria, as flutuações anuais dos mirídeos nocivos ao cacaueiro foram estudadas por ENTWISTLE (1964). 0 au tor observou que o pico da população de S. singularis apresentava variaçöes no decorrer dos anos, não tendo, entretanto, determinado os fatores que influenciavam nestas variaçós. YOUDEOWEY (1969) continuando com os trabalhos na Nigéria, rea lizou pesquisas visando o controle dessa praga. Na tentati- 
va de estabelecer as épocas de controle, aplicou inseticida quando a curva de flutuação era a mais baixa possível e assim conseguiu retardar o crescimento da população. Nas parcelas não tratadas o nível de infestação foi o dobro das parcelas pulverizadas com inseticidas.

BRUNEAU DE MIRE (1971) fez observações contínuas so bre a ecologia e o ciclo de estações dos mirídeos do cacau na República de Camarões, durante quatro anos em três áreas expe rimentais. Os dados conseguidos, mostraram a existência de pelo menos três tipos de flutuações numéricas: primeiro houve uma progressão constante, atē ser alcançado o nível de equilíbrio, havendo flutuações bimestrais intermeadas e rela cionadas a alternância de gerações, o que por sua vez correspondeu a uma infestação primária. A ocorrência de populaçóes não estacionais, também foi observada e este fenómeno pareceu estar associado a um choque qualquer, como a queda de àrvores, tratamento com inseticidas ou a uma reinfestação de ärvores que se regeneraram. Também foi observada uma variação cíclica anual de populações que alcançaram seu nivel de equilíbrio - qual incluiu um período de estabilidade, uma fase de progressão e outra de recessão, com repetições anuais, em épocas definidas, em cada uma das äreas estudadas. A análise do autor, permitiu observar uma correlação positiva entre o período de crescimento de população dos mirídeos e o desenvolvimen to do Eruto do cacaueiro. Observou ainda que a retirada dos frutos não afetou seriamente o ciclo de pragas, supondo as- 
sim que o período de progressão tenha correspondido a um determinado estado fisiológico do cacaueiro.

Os estudos realizados na Nigéria por EQUAGE (1977), relevaram que a população de $S$. singularis aumenta progressivamente com a proporção das ärvores infestadas no campo e o modelo de flutuação sazonal e a abundância relativa desse mirídeo, oscila com a variedade e a idade da planta.

Finalmente VILlACORTA (1977) estudou na Costa Rica, as relações entre a morte descendente do cacaueiro e as infes tações de Monalonion annulipes Sig. Os estudos foram realiza dos em áreas sombreadas e sem sombra e os resultados sugeri ram que os mirídeos são numerosos em äreas de cacau sem sombra, ocorrendo os maiores picos populacionais nas duas äreas, durante os meses de outubro e novembro. A disponibilidade de alimento para o inseto, assim como as oscilações de temperatu ra ambiente maiores de $89 \mathrm{C}$ e a alta umidade relativa foram os fatores que propiciaram a ocorrência de grandes infestações. Concluiu o autor que o sombreamento é importante para prevenir contra a morte descendente do cacaueiro, observando-se as sim, em äreas de pouca sombra, uma relação positiva entre o ataque dos mirideos nos brotos terminais das plantas e a intensidade da morte descendente das mesmas. 
3.2 - Insetos Pragas Associados a Cacauicultura Brasileira

$0 s$ insetos pragas do cacaueiro no Brasil, têm sido particularmente estudados nos Estados da Bahia e Espírito San to. BONDAR (1924 e 1936), contribuiu com as primeiras informa ções a respeito, culminando com a publicação de um relatório pioneiro, onde relacionou aproximadamente 100 espécies de insetos nocivos ao cacaueiro na Bahia (BONDAR, 1.939). Posterior mente, outras informações foram acumuladas com o decorrer do tempo, como as de costa LIMA (1949, 1953 , 1955 e 1956); SIL VA (1944 e 1957), as sinópses de D'ARAUJo e SIlva et alii (1968) e os registros de ABREU (1968) e SMITH (1972).

os estudos de flutuação de pragas em cacaueiro, adquiriram maior importância a partir dos primeiros trabalhos realizados na Região Cacaueira da Bahia.

VENTOCILla (1967) empregou a armadilha luminosa para determinar a flutuação populacional do coleóptero Amphix discoidea (Fabr.). SILVA et alii (1969) usaram a mesma técni ca na mesma região para estudar a periodicidade do vôo de in setos de häbitos noturnos em cacaueiro e construiram a curva de flutuação da mariposa Arsenura armida (Cr.). Segundo os autores, o pico populacional da praga ocorre entre os meses de março e abril. Ainda na Bahia, Ventocilla (1970), verifi cou que o cicadelídeo Empoasca sp. atinge os maiores niveis, durante os meses de janeiro a maio, ocorrendo maiores infesta ções em cacaueiros desprovidos de sombreamento definitivo. 
SHITE e VENTOCILLA (1971), investigaram o efeito da luz na tendência dos estragos provocados pelos tripes em cacaueiros no Espírito Santo e a influência de alguns fatores ambientais na incidência dos danos. Verificaram que os cacaueiros expostos a luz, sofreram maior ataque nos frutos e nas folhas que os cacaueiros sob sombreamento normal. Houve também uma interação positiva entre os diversos níveis de fru tificação do cacaueiro e o grau de ataque. A maior intensida de de ataque da praga, ocorreu entre os meses de março e agos to, coincidindo com os menores indices de precipitação pluvio mētrica.

ABREU (1971) estudou e estabeleceu as curvas de flu tuação do crisomelídeo Maecolaspis ornata (Germ.) e dos curcu 1ionídeos Lordops cilipes Germ, , Naupactus bondari Parsh. , Naupactus sp. e Lasiopus eilipes (Sah1b.). . Os resultados apresentados pelo autor, mostraram que entre as espécies estudadas, o crisomelídeo M. ornata é a mais importante, represen tando $4,3 \%$ do total dos indivíduos estudados. Houve tambēm uma correlação positiva altamente significativa entre os lançamentos de folhas novas do cacaueiro e a população de $M$. or nata, dois meses depois da ocorrência deste estado fenolög co. Quanto às outras espécies, esta relação foi a seguinte: Comoo L. aurosa as correlações foram positivas e significativas ao nível de $5 \%$ de probabilidade, um e dois meses após o 
lançamento. Com oN. bondari, a correlação foi positiva e significativa no mesmo mês, e, finalmente, para a população total, as anälises mostraram correlações positivas no mesmo mês, um mês depois mais significativamente, dois meses após o lança mento. Baseado nos resultados conseguidos o autor estabele ceu que as épocas de aplicação de inseticidas, devem coinci dir com o início de lançamento de folhas novas, isto é, quando a curva de população dessas pragas, ainda se encontra no seu nível mais baixo.

SMITH (1973), estudou a dinâmica populacional do Se Zenothrips rubrocinctus (Giard.) em cacaueiros do Espírito San to, tendo encontrado correlações positivas entre o nível da população com a frutificação até dois meses após o evento. Não encontrou nenhuma correlação positiva com o lançamento de folhas novas até quatro meses após a sua ocorrência. A preci pitação pluviométrica influenciou negativamente no crescimento da população e a temperatura também mostrou uma correlação negativa até quinze dias após sua manifestação. No entanto, três a quatro meses após, influenciou de forma positiva na po pulação da praga. Com base nesses dados, o autor recomendou que as medidas de controle a essa praga, devem ser postos em prática no início dos períodos de frutificação, após o apare cimento dos primeiros sintomas de "ferrugem". 
3.3 - Entomofauna do Cacaueiro na Amazônia

São escassas as informações sobre insetos associa dos ao cacaueiro nas áreas amazonicas. Uma das primeiras informações de ocorrência de insetos nocivos ao cacaueiro nessa região, foi feita por CALDEIRA e VIEIRA (1938) ao mencionarem a presença do fulgorídeo (Homóptera) Tragopa auriculata (0liv.) e das formigas Dolichoderus attelaboides Fabr., D. bidens L. e D. bispinosus L., causando danos ao cacaueiro no Estado do Pará. Posteriormente, SEFER (1961), citou como pra gas do cacaueiro na Amazônia, as espécies: Acromyrmex corona tus (Fabr.), Atta cephalotes (L.), A. sexdens (L.), Azteca chartifex (Fore1), A. paraensis (Roger), Selenothrips rubro cinctus (Giard) e Tragopa auriculata (01iv.).

CONDURU (1966), também mencionou a saūva e a formiga de enxerto Azteca paraensis bondari Borg. , como pragas do cacaueiro na Amazônia, não tecendo outros comentários a res peito.

SILVA e COSTA (1973) registraram em Belém, a presença de um curculionídeo que posteriormente foi descrito pelo Dr. E. Voss, como uma nova espécie (Plectrophorus incertus Voss.). Esse inseto foi coletado no Jardim Colonal do Serviço Experimental de Belém (Parä), causando ser̃ios danos às folhas dos cacaueiros.

VENTOCILLA (1975), constatou nas plantações de cacau do Núcleo Colonial do INCRA, em Rondônia, a presença de algumas pragas como serradores, coleobrocas e formigas doucei 
ras, vivendo em trofobiose com insetos sugadores, tais como os membracídeos Horiola sp.. A formiga caçarema Azteca char tifex spiriti Forel, tambëm foi citada pelo autor, em associa ção com o piolho Ceroplastodes sp.. Foram observados danos causados pelo Monalonion sp., entretanto não foi encontrado nenhum exemplar nas plantações. Outros insetos constatados foram o Oiketicus kirbyi (Lands-Guild), percevejos sugadores e lagartas do tipo "mede palmo".

No Estado do Amazonas, NASCIMENTO et ali $i$ (1975), observaram sintomas de ocorrência de pragas periódicas, tais co mo: Nodonota sp., Colaspis sp. e de MonaZonion sp., bem co mo a presença das formigas Solenopsis spp. (pixixica), Azteca sp. (caçarema) e Acromyrmex spp. e cupins. Não foi consta tada a presença de formigas do gênero Atta. 
4 - MATERIAIS E METTODOS

\section{1 - Características das Areas Experimentais}

As amostragens foram feitas em fazendas localizadas nas Regiões Bragantina e Guajarina, ambas no Estado do Pará. De acordo com a classificação de KOPPEN (1948), as regiões apresentam um clima tropical chuvoso dos tipos Afi e Ami, res pectivamente. A cobertura vegetal $\bar{e}$ composta em grande parte por capoeiras, plantações de cacau, pimenta do reino, cultu ras de subsistência, etc., evidenciando-se ainda, estreitas faixas de florestas densa e pujante, caracterizando a condi ção primitiva das áreas. Os solos são predominantemente do tipo 
latosol amarelo com textura que varia de leve a pesada e topo grafia plana a ondulada.

\section{2 - Fatores Climāticos}

Os dados referentes a Região Bragantina foram forne cidos pelo Laboratörio de Climatologia Agrícola da EMBRAPACEPATU, cujo posto de observação, está localizado na própria base física, sediada em Belém.

Os dados da Região Guajarina foram obtidos do Posto Meteorológico da Colónia Agrícola da JAMIC, distante $15 \mathrm{~km}$ da cidade de Tomé-Açü, onde estão concentradas as grandes plan tações do município.

4.3 - Estudo Fenológico do Cacaueiro.

Em cada região foram selecionadas áreas para coleta dos dados de lançamento de folhas novas, e do nümero de frutos maduros e pecos (frutos secos). Na Região Bragantina fo ram feitos 19 levantamentos enquanto que na Região Guajarina foram feitos apenas 13. 


\subsection{1 - Lançamento de folhas novas}

Para obtenção dos dados de folhas novas, foram sale cionados 10 cacaueiros e em cada um deles, marcaram-se 30 ra mos, distribuidos equitativamente, nos terços superior, médio e inferior da copa das plantas. 0s cacaueiros e os ramos selecionados receberam etiquetas de identificação que foram pre sas com auxilio de um fio de nylon. As contagens nos ramos selecionados, foram feitas semanalmente, conseguindo-se assim, os dados referentes ao número de folhas novas disponíveis durante cada mês estudado.

4.3.2 - Contagem do nümero de frutos maduros.

Selecionaram-se 20 cacaueiros ao acaso e as conta gens foram feitas a medida que os frutos foram colhidos, tendo-se assim, os dados relativos ao número total de frutos maduros em cada mês.

\subsection{3 - Contagem do nümero de frutos pecos,}

Com auxílio de 20 tabuleiros de madeira com fundo telado e ärea de $1 \mathrm{~m}^{2}$ cada, foram feitos os levantamentos mensais do número de frutos pecos. Cada tabuleiro foi colocado sob a copa de uma planta e assim, mensalmente os frutos coletados foram separados e contados. 
4.4 - Levantamento dos Insetos

Para o levantamento dos insetos procedeu-se da seguinte maneira:

Em cada região foram selecionadas quatro propriedades distribuidas estrategicamente e em cada uma delas, fizeram-se as amostragens mensais das populações de insetos, apli cando-se B.H.C. $12 \%$ em seis cacaueiros escolhidos ao acaso. os insetos foram coletados duas horas após cada tratamento, em lençois de $4 \times 4$ metros, estendidos previamente sob e em volta de cada cacaueiro palvilhado. As aplicações mensais obedeceram ao regime de rotatividade conforme foi preconizado por SOUTHWOOD (1971). No Brasil esse método foi utilizado por ABREU (1971) na ärea cacaueira do Espírito Santo.

Após coletados, os insetos foram acondicionados em vidros contendo álcool $70 \%$ e posteriormente foram separados, contados e identificados pelos diversos especialistas de cada grupo taxonômico.

4.5 - Indice de Diversidade ( $\alpha)$

A relação entre o nümero de espécies e o nümero de individuos de cada comunidade foi calculada, seguindo-se a fórmula proposta por Margalef e citada por SOUTHWOOD (1971):

$$
\alpha=\frac{S-1}{L N},
$$

onde: 
E é o nümero de espécies da comunidade;

L $N$ e o logarítmo neperiano do número de indivíduos.

4.6 - Constância das Espécies

Bodenheimer, citado por SILVEIRA NETOet alii (1976), classifica as espécies em constantes, acessórias e acidentais, de acordo com a presença de cada uma delas nos levantamentos fetuados. Assim, as espécies constantes são aquelas que estão presentes em mais de $50 \%$ das coletas; espécies acessórias são as que estão presentes em 25 a $50 \%$ das coletas e espécies acidentais são as que estão presentes em menos de $25 \%$ das coletas efetuadas.

A constância foi calculada através da fórmula

$$
\mathrm{C}=\frac{\mathrm{p} \times 100}{\mathrm{~N}}
$$

onde, $\underline{p}$ e o nümero de coletas contendo a espécie estudada; N é o número total de coletas efetuadas.

\section{7 - Frequência das Espécies}

A frequência de cada espécie nas duas regiões estudadas foi calculada através da porcentagem de indivíduos de uma espécie em relação ao total de indivíduos coletados. 
4.8 - Quociente de Similaridade (QS)

o grau de semelhança entre as duas comunidades, em termos de espécies, foi calculado através da fórmula proposta POr SORENSEN (1948):

$$
Q S=\frac{2 j}{a+b} \text {, }
$$

onde, a é o nümero de espécies no habitat $A$;

b é o número de espécies no habitat $B$;

ja é o número de espécies comuns nos dois habitats.

\section{9 - Flutuação}

Para o estudo da flutuação de população, foram sele cionadas apenas as espécies constantes. A flutuação popula cional de cada espécie foi confrontada com os fenômenos climä ticos e fenológicos do cacaueiro.

\subsection{0 - Anālise dos Dados}

A anālise da flutuação populacional das espécies constantes com os dados meteorolögicos e fenológicos do cacaueiro, foi feita pelo cálculo do coeficiente de correlação linear simples $(r)$ e o coeficiente de regressão linear mü1tipla (R), segundo DRAPER e SMITH (1966). 
Para o cálculo da regressão mültipla, foram usadas as variáveis independentes, temperatura do ar $\left(X_{1}\right)$, umidade relativa do ar $\left(x_{2}\right)$, precipitação pluviométrica $\left(X_{3}\right)$, lanf̧a mento de folhas novas $\left(x_{4}\right)$, frutos maduros $\left(x_{5}\right)$ e frutos pe$\cos \left(x_{6}\right)$

A escolha das equações de regressão, baseou-se nos seguintes critérios:

a - Significância da equação, por ordem de importância das variāveis.

b - Porcentagem da explicação do fenômeno atravēs do coefí ciente de determinação.

0 teste da regressão mültipla é explicado pelo valor de F.

As anālises foram desenvolvidas no computador da Unidade de Frocessamento de Dados, anexo ao Departamento de Ma temätica e Estatistica da E. S. A. "Luiz de Queiroz" - USP, em Piracicaba, SP. 
Os resultados obtidos nos levantamentos das duas re giões, estão representados nas Tabelas 1 e 2 , onde os inse tos aparecem em ordem alfabética de acordo com a ordem, famí lia e espécie. São tambēm apresentados na mesma tabela, o nū mero de individuos coletados mensalmente, a constancia e a frequência das espécies. 


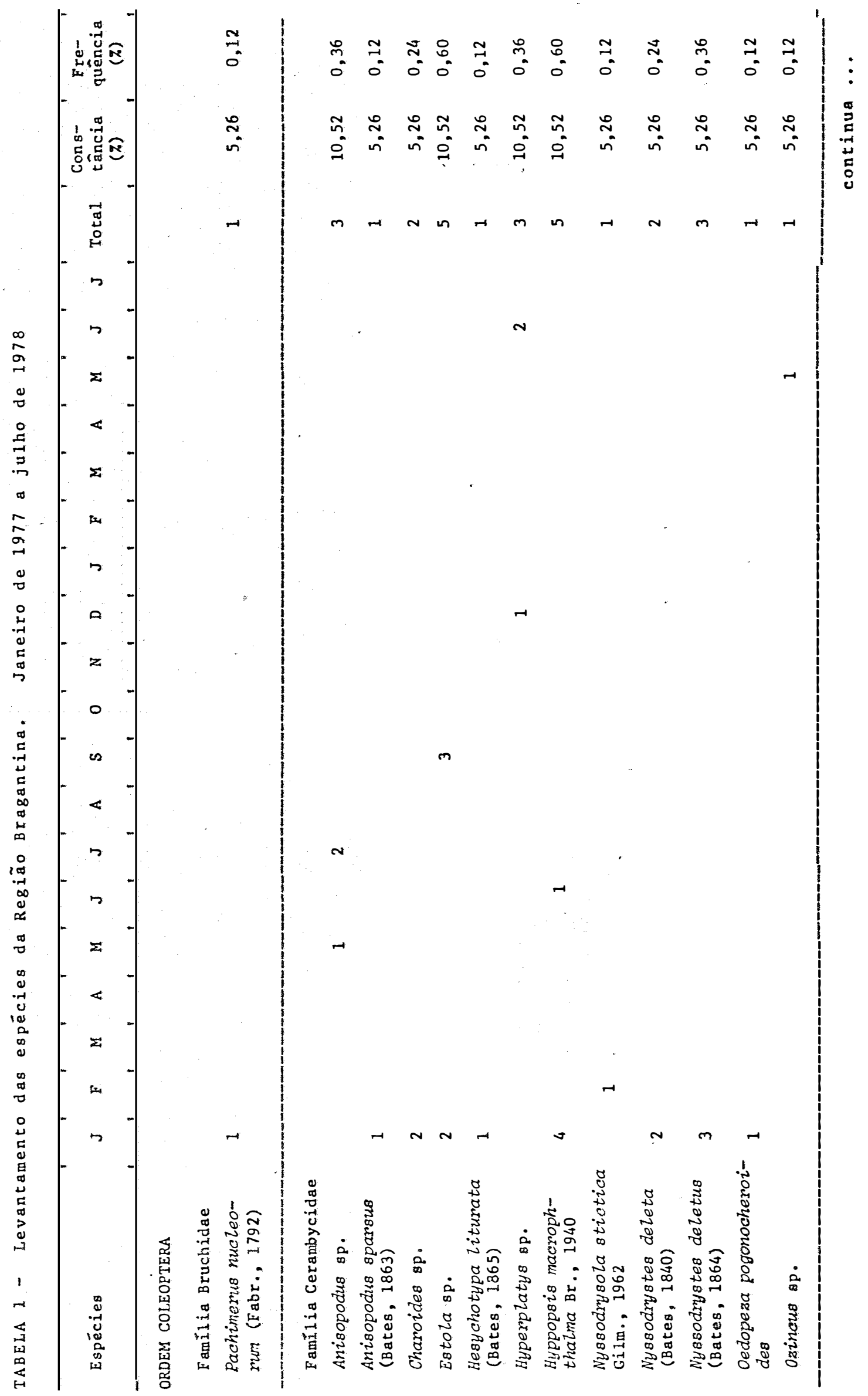




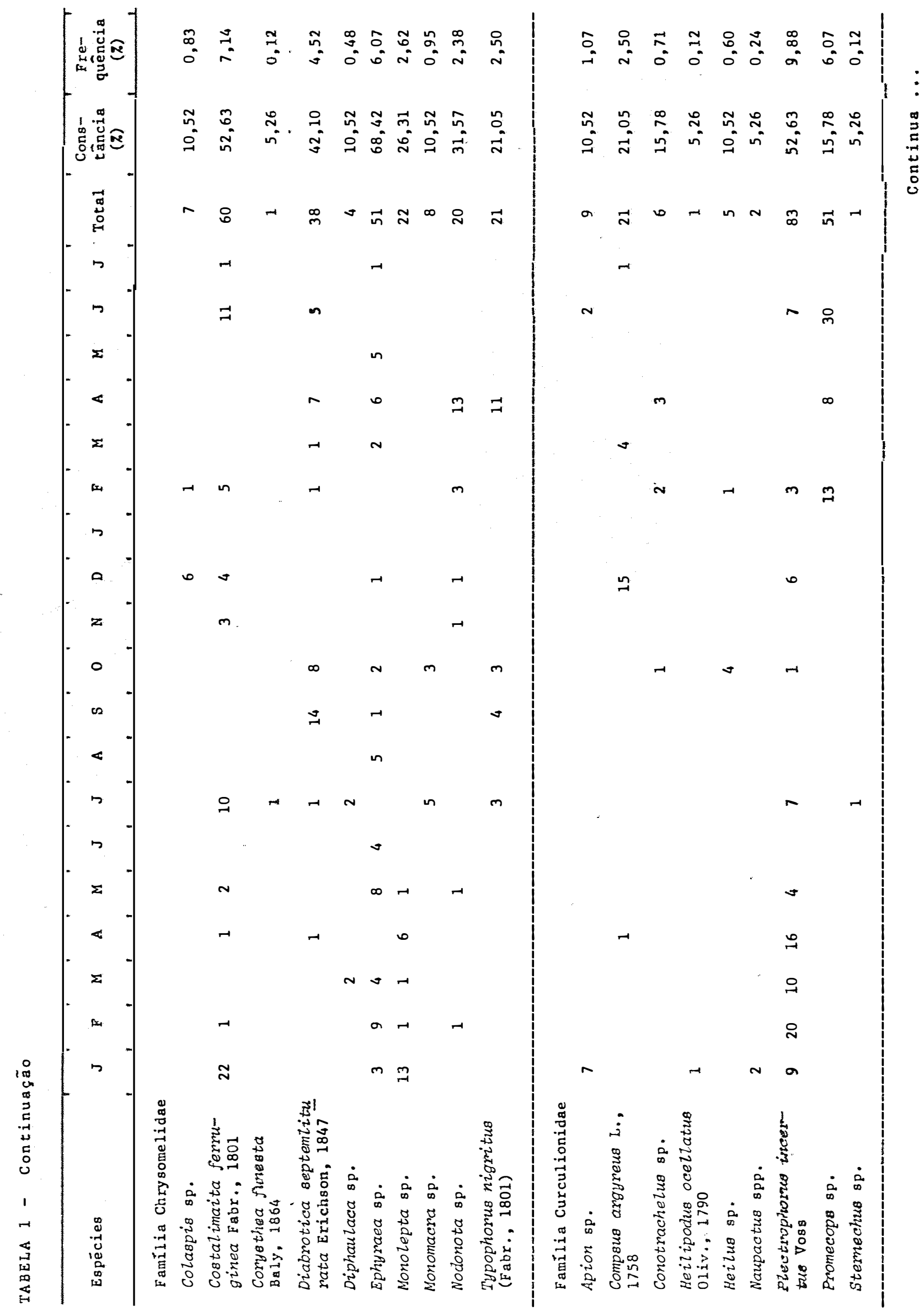




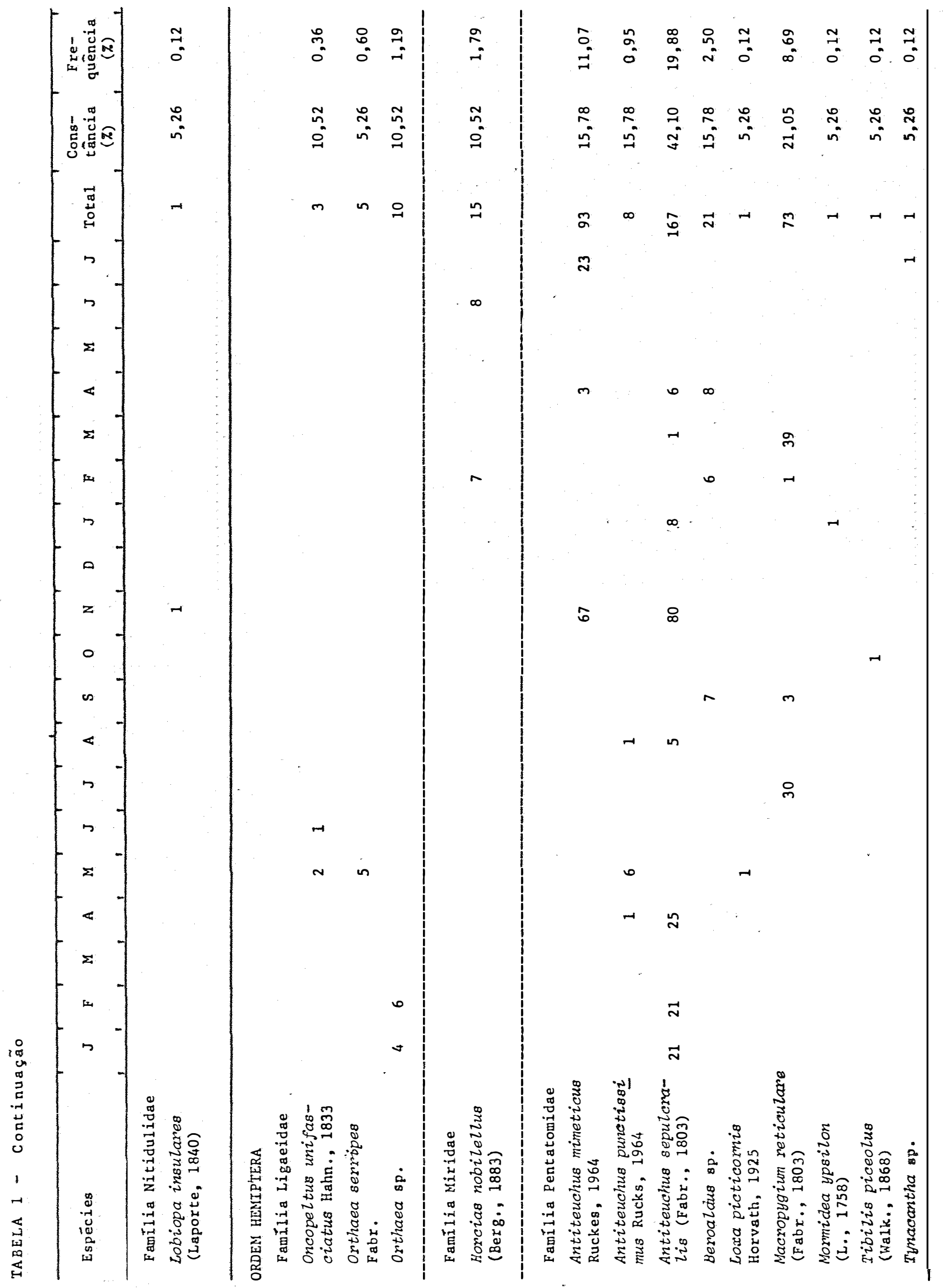




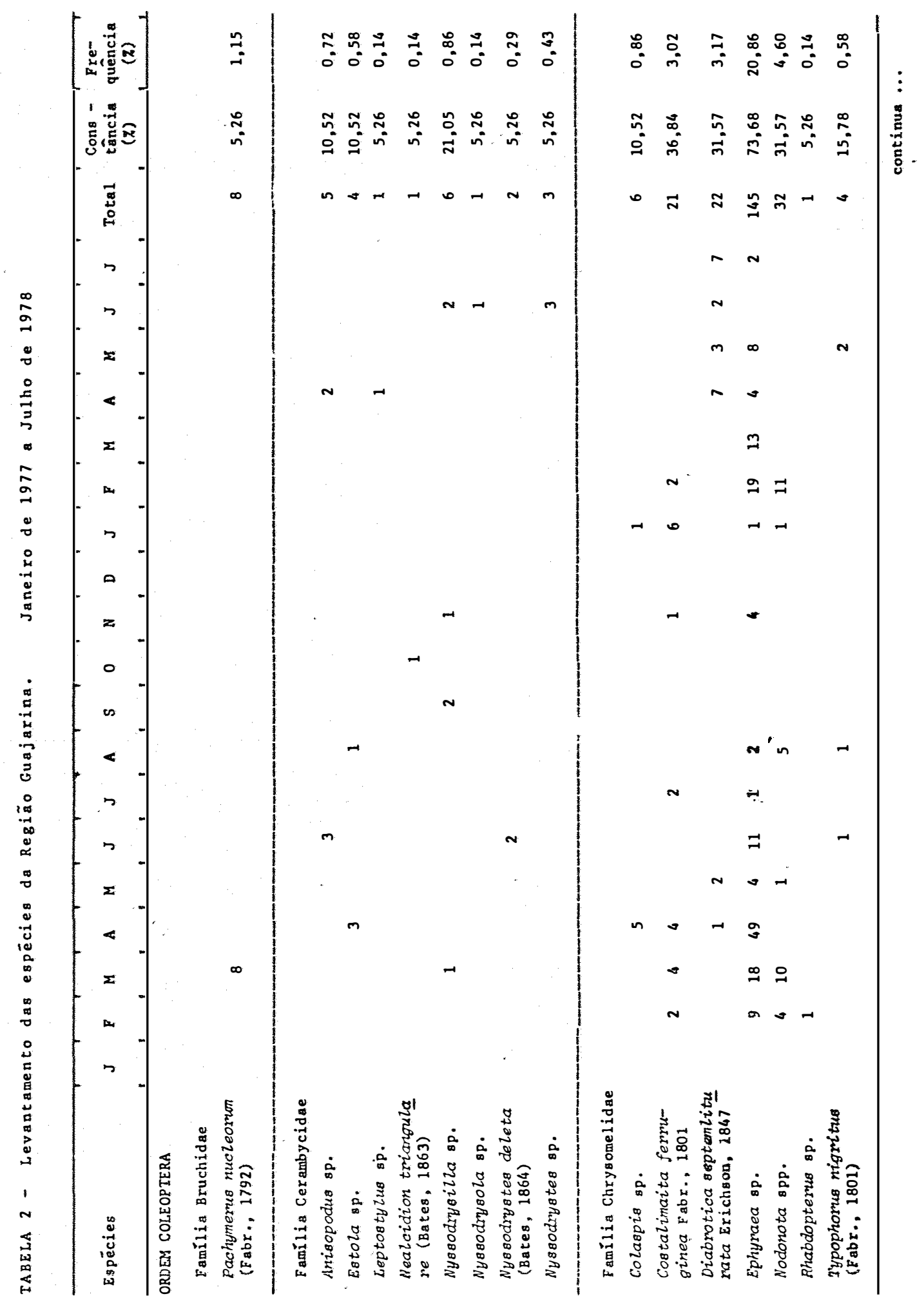




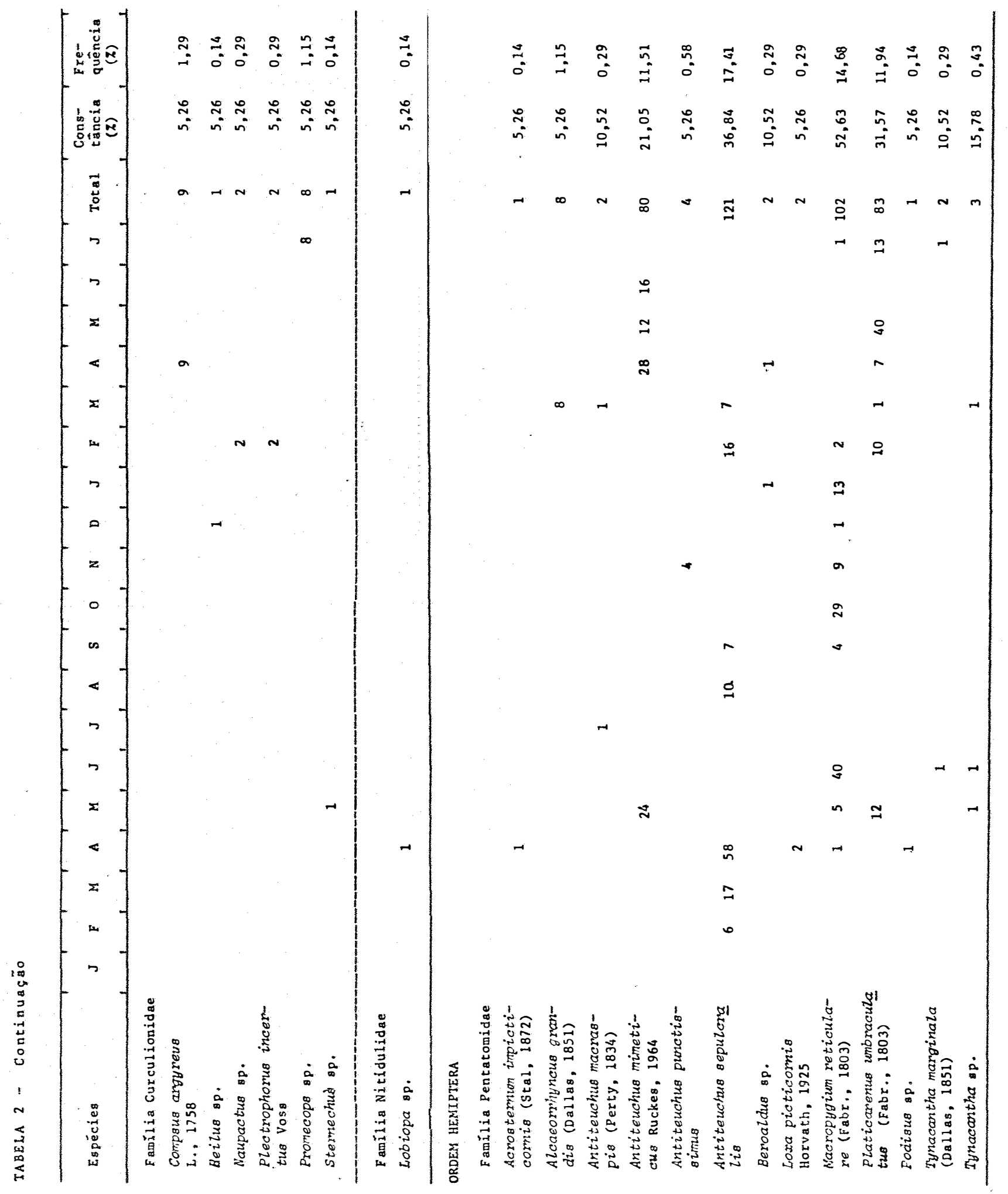


0 número de famílias, espécies e indivíduos bem como o Indice de diversidade das duas regiöes e o quociente de similaridade entre as mesmas, estão assim distribuidos:

\section{$\underline{\text { Região Bragantina: }}$}

$$
\begin{aligned}
& \text { Nümero de famílias ...... } 8 \\
& \text { Número de espécies ...... } 46 \\
& \text { Número de indivíduos .... } 840 \\
& \text { Indice de diversidade ( } \alpha \text { ). } 6,7
\end{aligned}
$$

$\underline{\text { Região Quajarina: }}$

$$
\begin{aligned}
& \text { Nümero de famílias ...... } 6 \\
& \text { Número de espécies ...... } 36 \\
& \text { Número de indivíduos .... } 695 \\
& \text { Indice de diversidade }(\alpha) \text {. } 5,3 \\
& \text { Quociente de similaridade (Q.S.) } 58,5 \%
\end{aligned}
$$

Pelos resultados nos levantamentos, observa-se que 82 espécies foram coletadas na área cacaueira do Estado do Pa rä. Deve-se acrescentar ainda que cerca de 20 espécies de ca da região, deixaram de ser catalogadas pela impossibilidade de identificação das mesmas.

Nos trabalhos realizados na Amazônia, nenhuma referência è feita às espécies coletadas, a excessão das observações realizadas por SILVA e COSTA (1973), quando constaram a presença de Plectrophorus incertus, atacando folhas de cacaueiro, em Belém (PA) e a citação de VEnTocilla (1975) que em Rondônia observou a presença de percevejos sugadores associados ao cacaueiro. 
Na Região Bragantina foram coletados 840 indivíduos, distribuídos entre 46 espécies, com um indice de diversidade igual a 6,7 , enquanto que na Região Guajarina o nümero de in divíduos foi de 695 com 36 espécies e um indice de diversidade equivalente a 5,3. Através destes resultados, nota-se que a primeira região apresenta uma fauna mais numerosa e diversi ficada que a segunda, supondo-se assim que nesta, os fatores limitantes, bem como a competição interespecífica estejam exercendo uma influência marcante na distribuição das espécies. Através do cálculo da constância, observa-se ainda que a Região Bragantina, possui 3 espécies constantes, 4 acessörias e 39 acidentais. A Região Guajarina possui 2 es pécies consantes, 3 acessórias e 31 acidentais. Nota-se por tanto, um nümero muito reduzido de espécies constantes, ou sẹ ja, de espécies que possimelmente jā estejam adaptadas a cultura, enquanto que, as espécies acessórias e, principalmente as acidentais, no momento, ainda se constituem numa incógnita no que diz respeito a associação com a cultura do cacaueiro. A explicação para esse fenômeno é dada através da teoria de "Colonização de I Ihas" proposta por McArthur e Wilson,em 1967, segundo a qual, quando uma cultura $\bar{e}$ instalada numa determina da área, a fauna que migra para essa nova vegetação é aquela existente nas äreas circunvizinhas, sejam elas, matas, capoe ras ou culturas diversas. Com o crescimento territorial da nova vegetação através dos anos, muitas desas espécies emigram, outras tendem a ser extintas pela competição interespe- 
cifica, enquanto aquelas que melhor se adaptarem, permanecem na nova cultura. Essa atividade intensa, dentro do novo habitat, tende a estabilizar-se posteriormente até que seja atingido o nível de equilíbrio (PRICE e WALDBAUER, 1975). Os resultados da frequência das espécies nas duas regiões, estão evidenciados nas Tabelas 1 e 2 . Na Região Bragantina a variação foi de $0,12 \%$ a $19,88 \%$, sendo que a es pécie de maior frequência foi o pentatomídeo Antiteuchus sepulcralis. Na Região Guajarina, a frequência oscilou de $0,14 \%$ a $20,86 \%$ e o crisomelídeo Ephyraea sp. foi a espécie mais frequente, evidenciando-se ainda o pentatomídeo Macropy gium reticulare com $14,68 \%$ de frequência. Nota-se portan to, que apenas três espēcies nas duas regiões, tiveram uma frequência mais destacada. Como são regiões que se caracterizam por uma exploração agrícola bastante diversificada, plenamente justificável a existência de uma entomofauna hete rogênea e composta de espécies pouco populosas que não atin giram ainda o ponto de equilíbrio.

\section{2 - Flutuação.}

Com base nos dados do levantamento, foram selecionadas as espécies representadas nas Figuras de 1 a 5 , cuja distribuição mensal e nümero total de indivíduos, bem como a constância, podem ser melhor visualizadas na Tabela 3. 


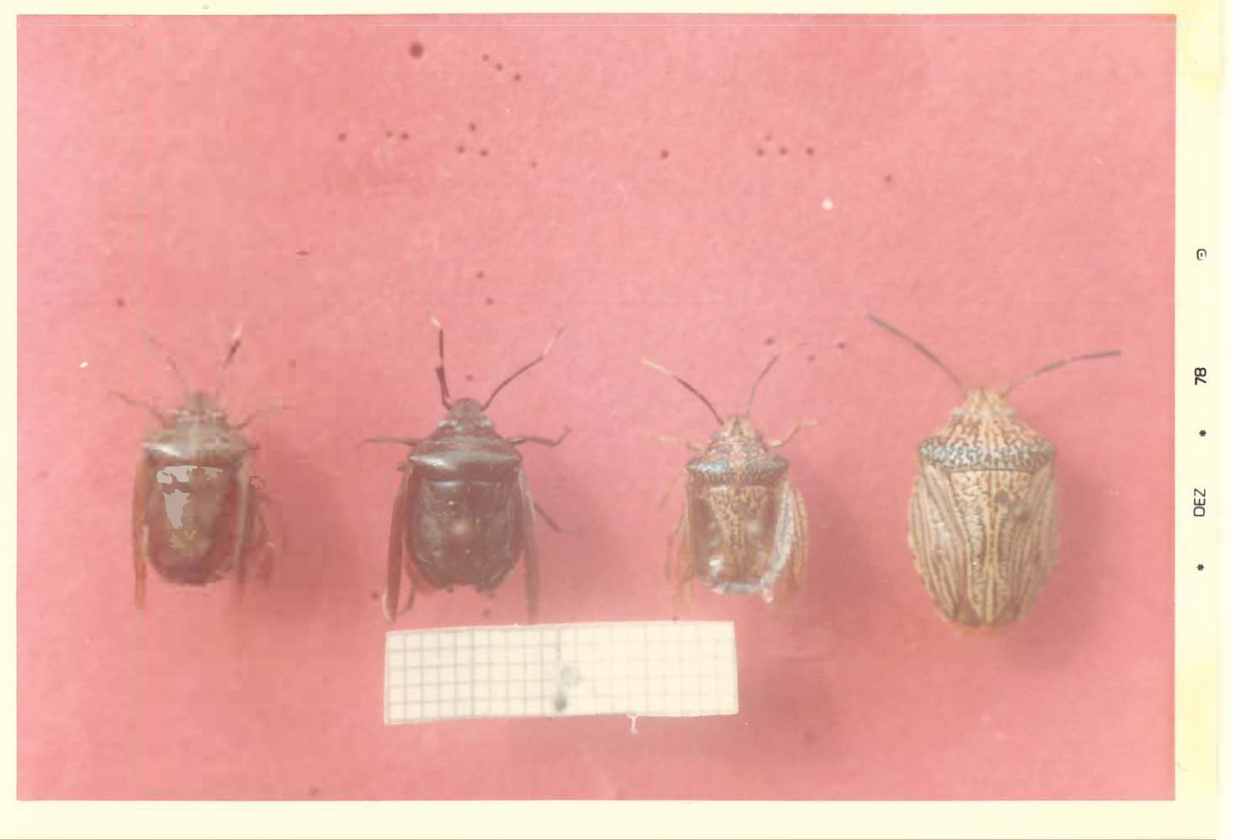

Fig. 1 - Antiteuchus spp. 


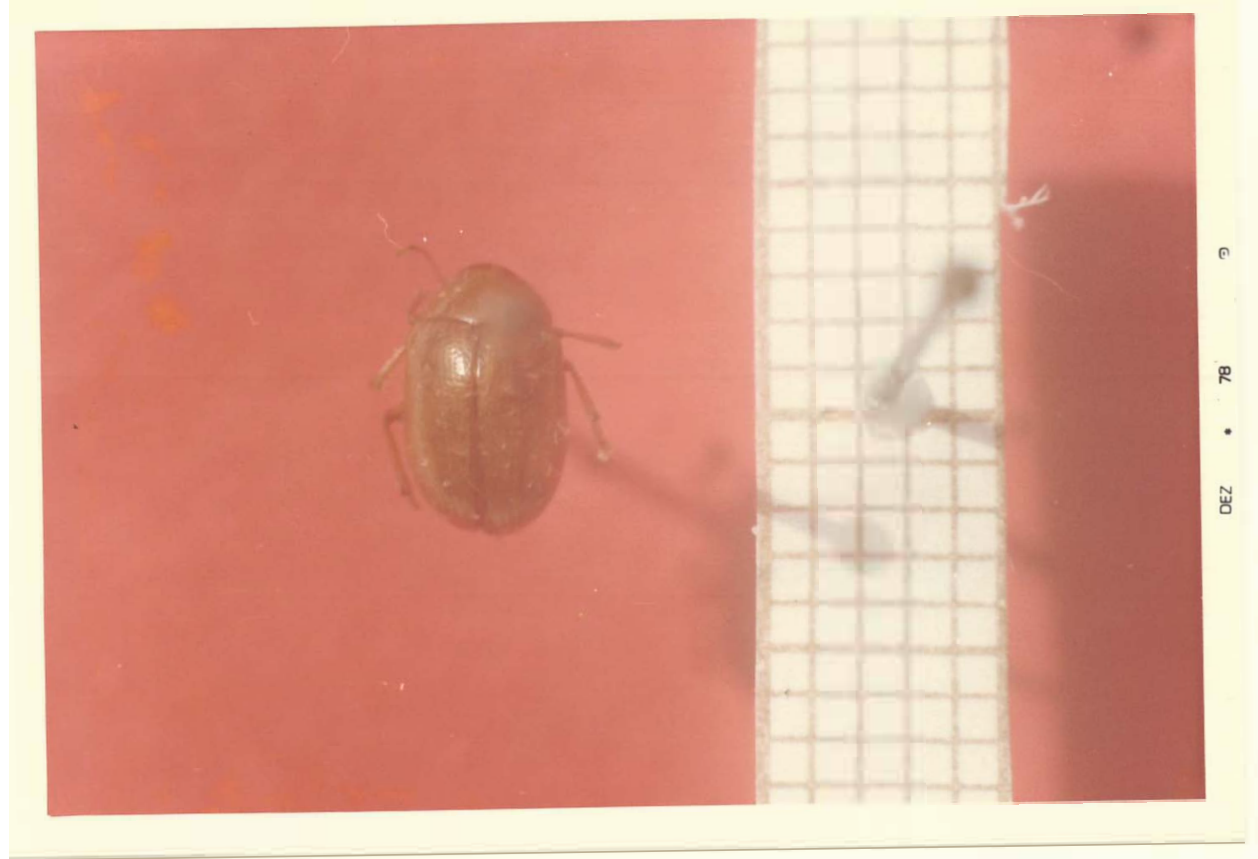

Fig. 2 - Costalimaita ferruginea Fabr., 1801 


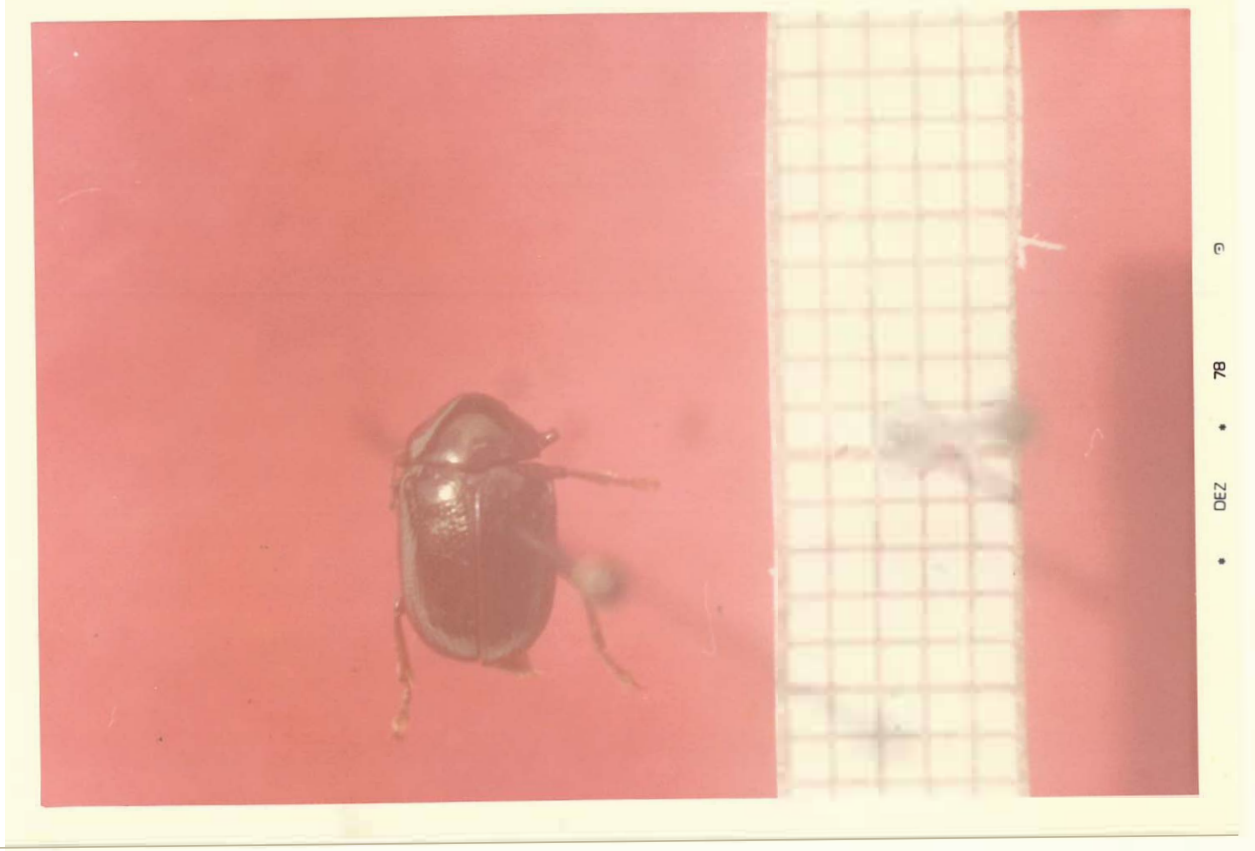

Fig. 3 - Ephyraea sp. 


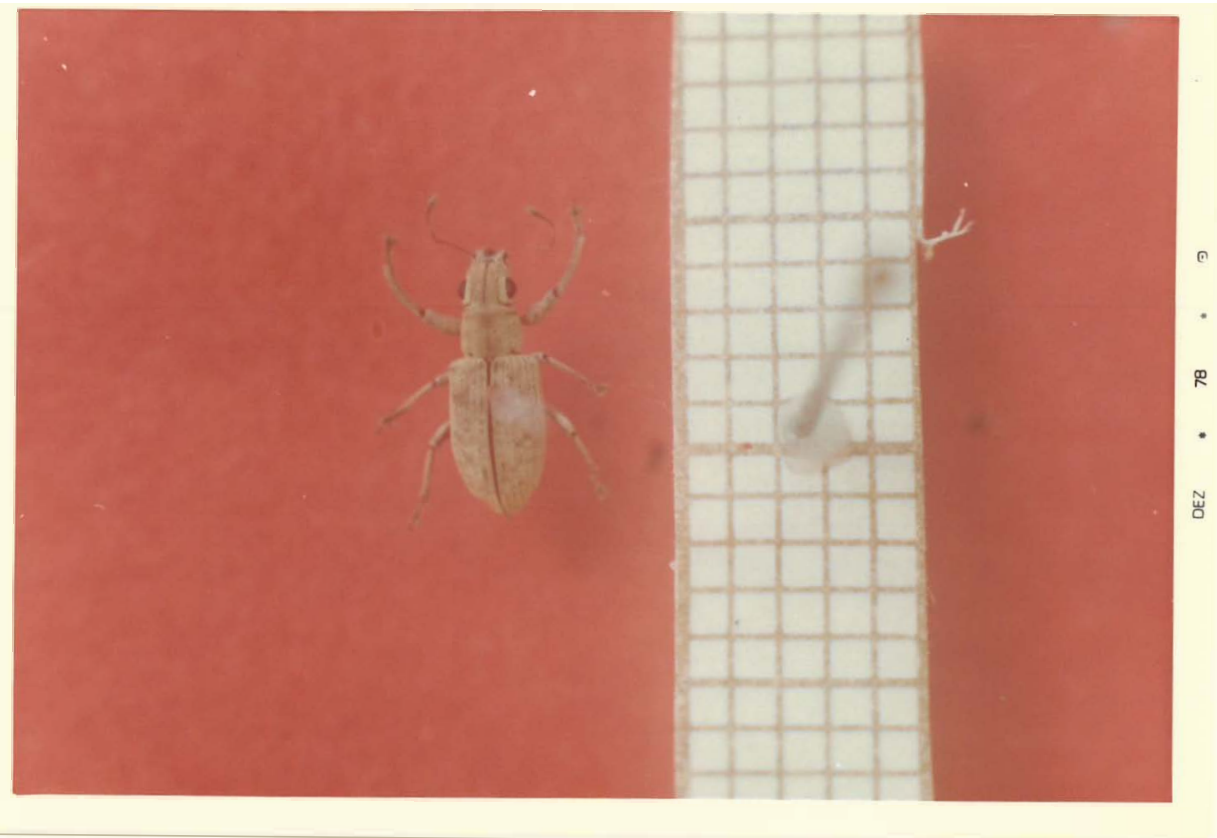

Fig. 4 - Plectrophorus incertus Voss 
35.

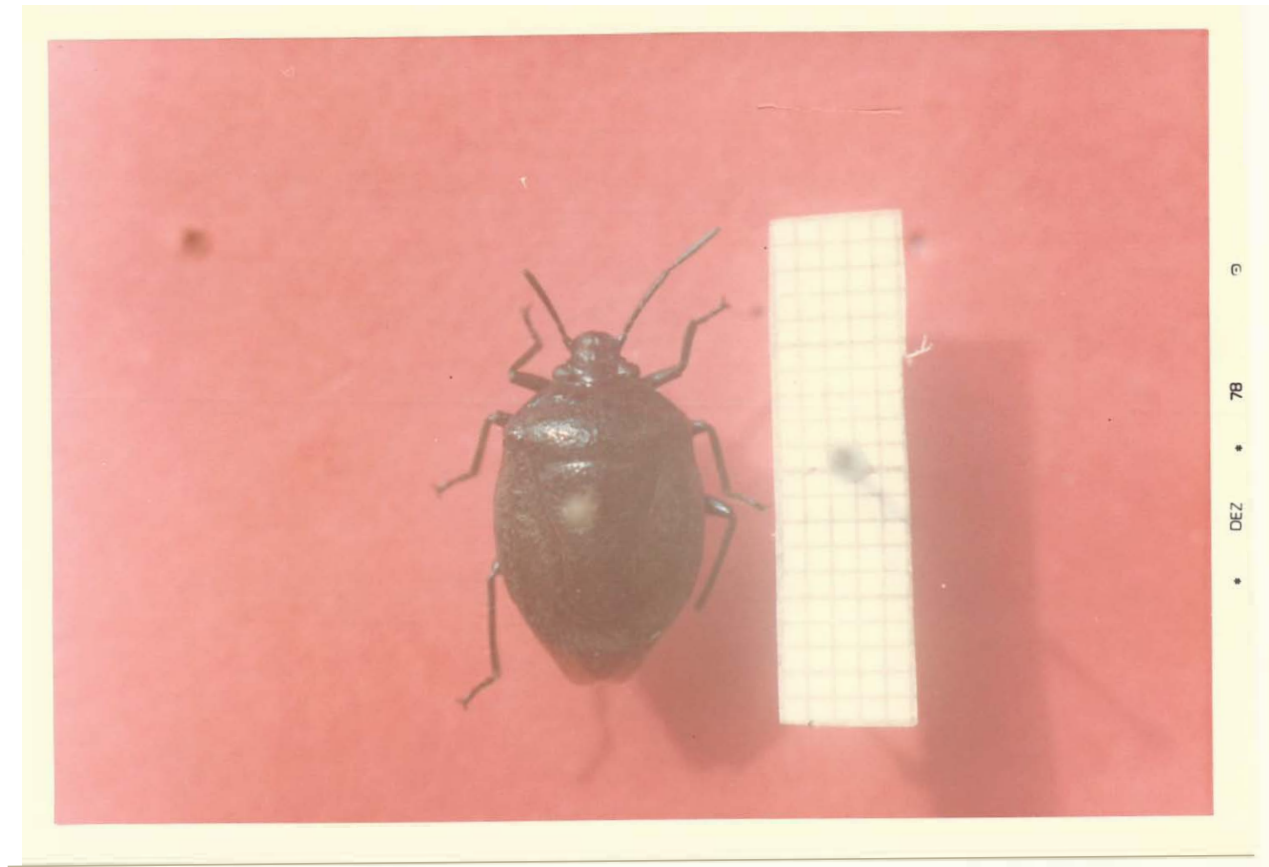

Fig. 5 - Macropygium reticulare (Fabr., 1803) 


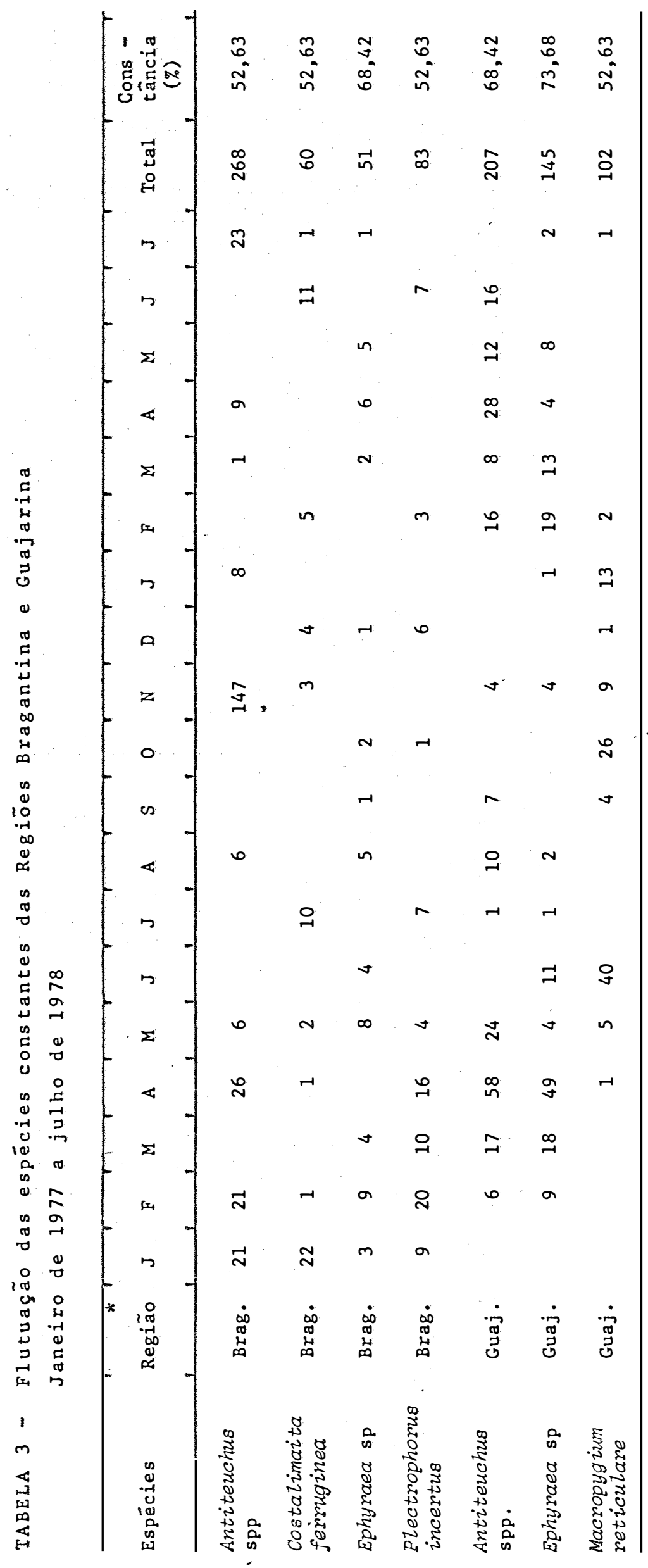


os insetos escolhidos para flutuação, foram aqueles que se mostraram constantes durante os levantamentos, sendo que as espëcies, Antiteuchus mimeticus, A. punctissimus e A. se pulcralis, todos da Região Bragantina, foram agrupados para esse estudo, por apresentarem características semelhantes.de ataque. As espécies de Antiteuchus macraspis, A. mimeticus, A. punctissimus e A. sepulcralis da Região Guajarina, também foram agrupadas a exemplo das espécies da Região Bragantina.

os dados meteorológicos e fenológicos do cacaueiro estäo representados nas Tabelas de 4 a 7 . A confrontação destes fatores com a flutuação populacional de cada espécie constante, encontramse nas Figuras de 6 a 12.

Os resultados das anālises de regressão mültipla,es tão resumidos nas Tabelas 8 e 9 , em ordem decrescente de importância, de acordo com a contribuição de cada variável. na flutação das espécies. 
TABELA 4 - Dados climáticos da Região Bragantina (Pa). Janeiro de 1977 a Julho de 1978

\begin{tabular}{lccc}
\hline Meses & $\begin{array}{c}\text { Temperatura } \\
\text { média } \\
(\% \mathrm{C})\end{array}$ & $\begin{array}{c}\text { Umidade } \\
\text { relativa } \\
(\%)\end{array}$ & $\begin{array}{c}\text { Precipitação } \\
\text { pluviométrica } \\
(\mathrm{mm})\end{array}$ \\
\hline Janeiro & 25,8 & 87,2 & 297,7 \\
Fevereiro & 25,3 & 90,0 & 463,8 \\
Março & 25,7 & 89,0 & 323,4 \\
Abril & 26,1 & 88,8 & 441,5 \\
Maio & 26,2 & 86,4 & 238,9 \\
Junho & 26,3 & 82,2 & 175,8 \\
Julho & 26,2 & 80,3 & 171,7 \\
Agosto & 26,4 & 80,6 & 136,9 \\
Setembro & 26,5 & 81,8 & 226,3 \\
Outubro & 26,8 & 78,2 & 123,3 \\
Novembro & 27,1 & 76,4 & 52,6 \\
Dezembro & 26,7 & 83,0 & 290,1 \\
Janeiro & 25,9 & 88,3 & 457,2 \\
Fevereiro & 26,6 & 86,5 & 360,6 \\
Março & 25,7 & 88,9 & 536,2 \\
Abril & 26,1 & 82,2 & 437,8 \\
Maio & 26,8 & 84,5 & 255,7 \\
Junho & 26,5 & 79,7 & 81,9 \\
Julho & 26,1 & 81,1 & 135,9 \\
\hline
\end{tabular}

Fonte: Laboratório de Climatologia Agrícola (EMBRAPA - CAPATU) - Pa. 
TABELA 5 - Dados climáticos da Região Guajarina (Pa). Janeiro de 1977 a Julho de 1978

\begin{tabular}{|c|c|c|c|}
\hline Meses & $\begin{array}{c}\text { Temperatura } \\
\text { média } \\
\text { (oC) }\end{array}$ & $\begin{array}{c}\text { Umidade } \\
\text { relativa } \\
(\%)\end{array}$ & $\begin{array}{c}\text { Precipitação } \\
\text { pluviométrica } \\
\text { (mm) }\end{array}$ \\
\hline Janeiro & 27,6 & 85,6 & 393,3 \\
\hline Fevereiro & 27,0 & 85,1 & 406,3 \\
\hline Março & 26,7 & 84,2 & 434,1 \\
\hline Abril & 27,8 & 85,1 & 418,8 \\
\hline Maio & 27,9 & 80,8 & 339,7 \\
\hline Junho & 27,6 & 77,8 & 134,7 \\
\hline JuIho & 27,0 & 76,4 & 114,3 \\
\hline Agos to & 27,4 & 74,0 & 75,3 \\
\hline Seterbo & 27,9 & 76,8 & 79,0 \\
\hline Outubro & 28,3 & 68,9 & 10,7 \\
\hline Noverabro & 28,6 & 65,3 & 18,1 \\
\hline Dezembro & 28,3 & 74,2 & 184,0 \\
\hline Janeiro & 26,2 & 86,8 & 401,1 \\
\hline Tevereiro & 27,0 & 85,1 & 353,0 \\
\hline Março & 26,0 & 87,0 & 689,1 \\
\hline Abril & 26,5 & 86,1 & 461,9 \\
\hline Ifaio & 27,0 & 81,5 & 326,2 \\
\hline Junho & 28,0 & 78,0 & 135,0 \\
\hline JuI ho & 27,0 & 76,0 & 114,0 \\
\hline
\end{tabular}

Fonte: Posto Meteorológico da JAMIC (Pa) 
TABELA 6 - Dados fenológicos de cacaueiros da Região Bragantina ( $\mathrm{Pa}$ ). Janeiro de 1977 a Ju 1ho de 1978

\begin{tabular}{|c|c|c|c|}
\hline \multirow{2}{*}{ Meses } & \multirow{2}{*}{$\begin{array}{c}\text { Número de folhas } \\
\text { novas }\end{array}$} & \multicolumn{2}{|c|}{ Número de frutos } \\
\hline & & Maduros & Pecos \\
\hline Janeiro & 350,0 & 500,0 & 235,0 \\
\hline Fevereiro & 500,0 & 370,0 & 80,0 \\
\hline Março & 155,0 & 245,0 & 95,0 \\
\hline Ab ril & 270,0 & 50,0 & 160,0 \\
\hline Maio & 347,0 & 70,0 & 20,0 \\
\hline Junho & 342,0 & 170,0 & 185,0 \\
\hline JuIho & 189,0 & 49,0 & 7,0 \\
\hline Agos to & 122,0 & 15,0 & 51,0 \\
\hline Setembro & 257,0 & 9,0 & 141,0 \\
\hline Outubro & 34,0 & 9,0 & 154,0 \\
\hline Novembro & 34,0 & 72,0 & 110,0 \\
\hline Dezembro & 214,0 & 216,0 & 132,0 \\
\hline Janeiro & 100,0 & 179,0 & 170,0 \\
\hline Fevereiro & 62,0 & 56,0 & 33,0 \\
\hline Março & 81,0 & 60,0 & 41,0 \\
\hline Abril & 169,0 & 37,0 & 24,0 \\
\hline Maio & 89,0 & 97,0 & 13,0 \\
\hline Junho & 169,0 & 35,0 & 4,0 \\
\hline Julho & 94,0 & 21,0 & 3,0 \\
\hline
\end{tabular}


TABELA 7 - Dados fenológicos de cacaueiros da Região Guajarina (Pa). Julho de 1977 a Julho de 1978

\begin{tabular}{lcrr}
\hline Meses & Nümero de folhas & Número de frutos \\
\hline novas & Maduros & Pecos \\
\hline Agosto & 86,0 & 16,0 & $1.028,0$ \\
Setembro & 254,0 & 13,0 & 58,0 \\
Outubro & 245,0 & 1,0 & 10,0 \\
Novembro & 305,0 & 6,0 & 15,0 \\
Dezembro & 79,0 & 3,0 & 80,0 \\
Janeiro & 452,0 & 52,0 & 310,0 \\
Fevereiro & 128,0 & 62,0 & 38,0 \\
Março & 84,0 & 87,0 & 89,0 \\
Abril & 56,0 & 24,0 & 382,0 \\
Maio & 72,0 & 70,0 & $1.018,0$ \\
Junho & 56,0 & 117,0 & $1.654,0$ \\
Julho & 110,0 & 238,0 & 10,0 \\
\hline
\end{tabular}




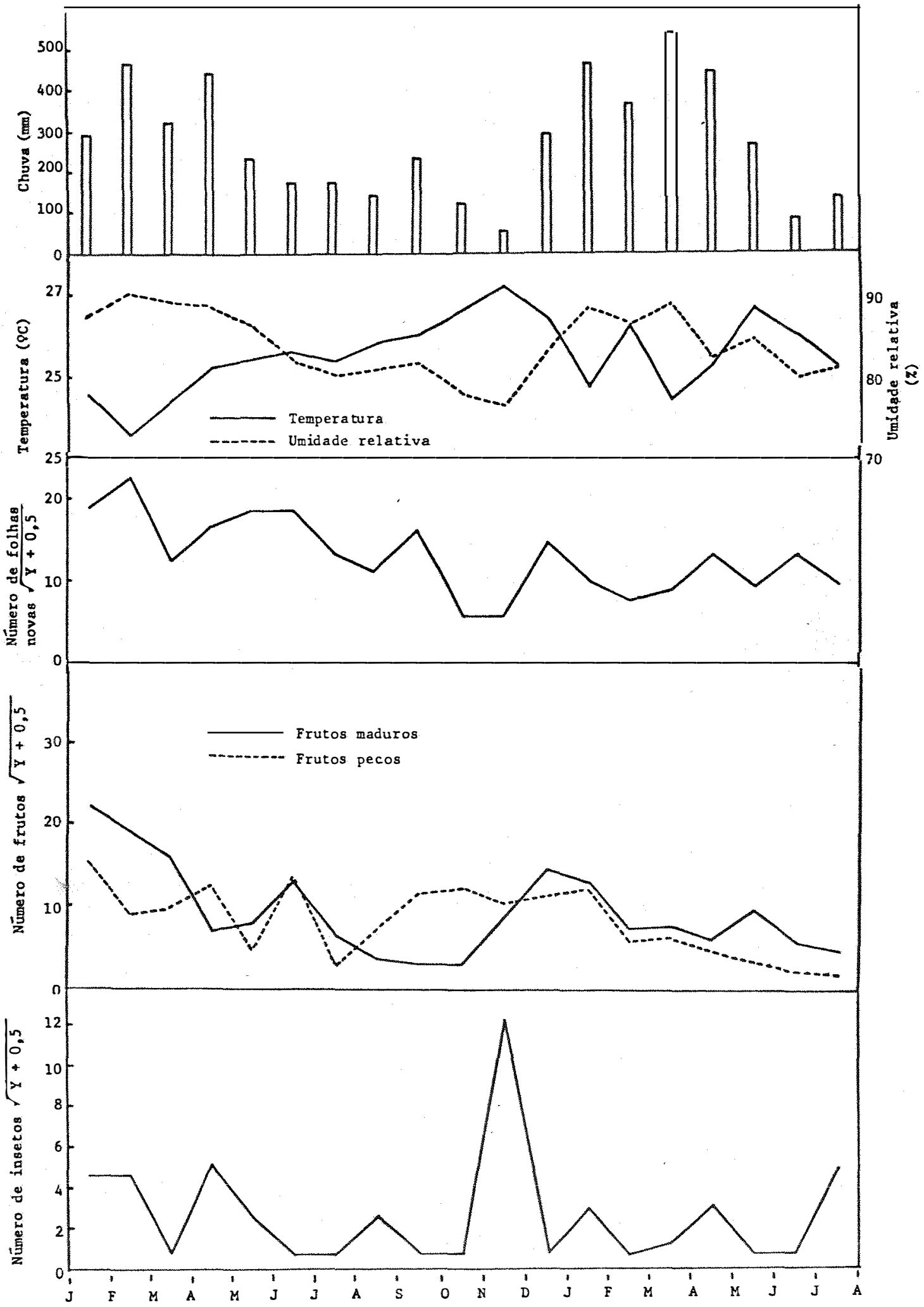

Fis. 6 - Flutuação populacional de Antiteuchus spp. em confronto com os fatores climáticos e fenológicos, do cacaueiro na Regiäo Bragantina (Pa) 


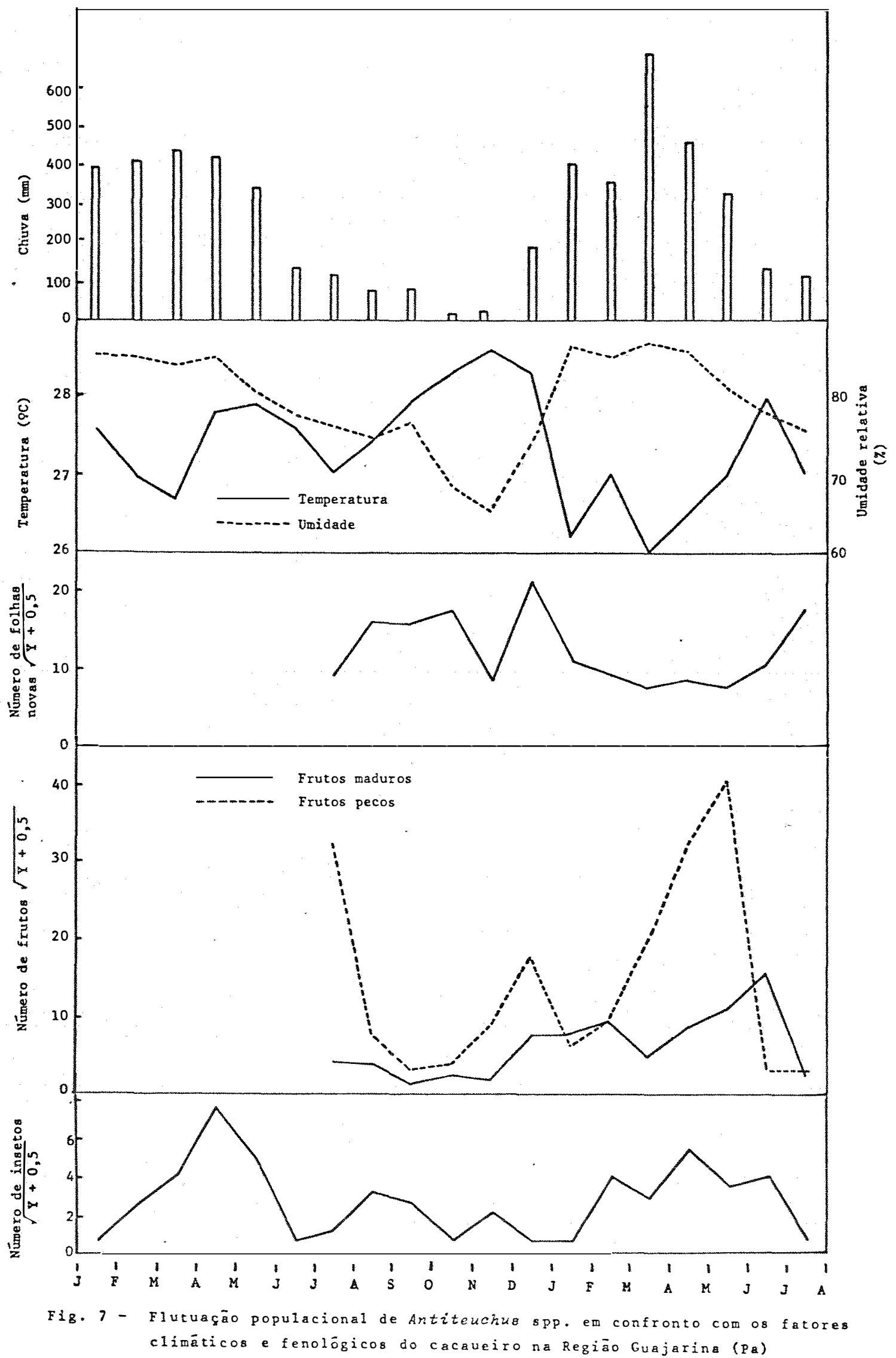




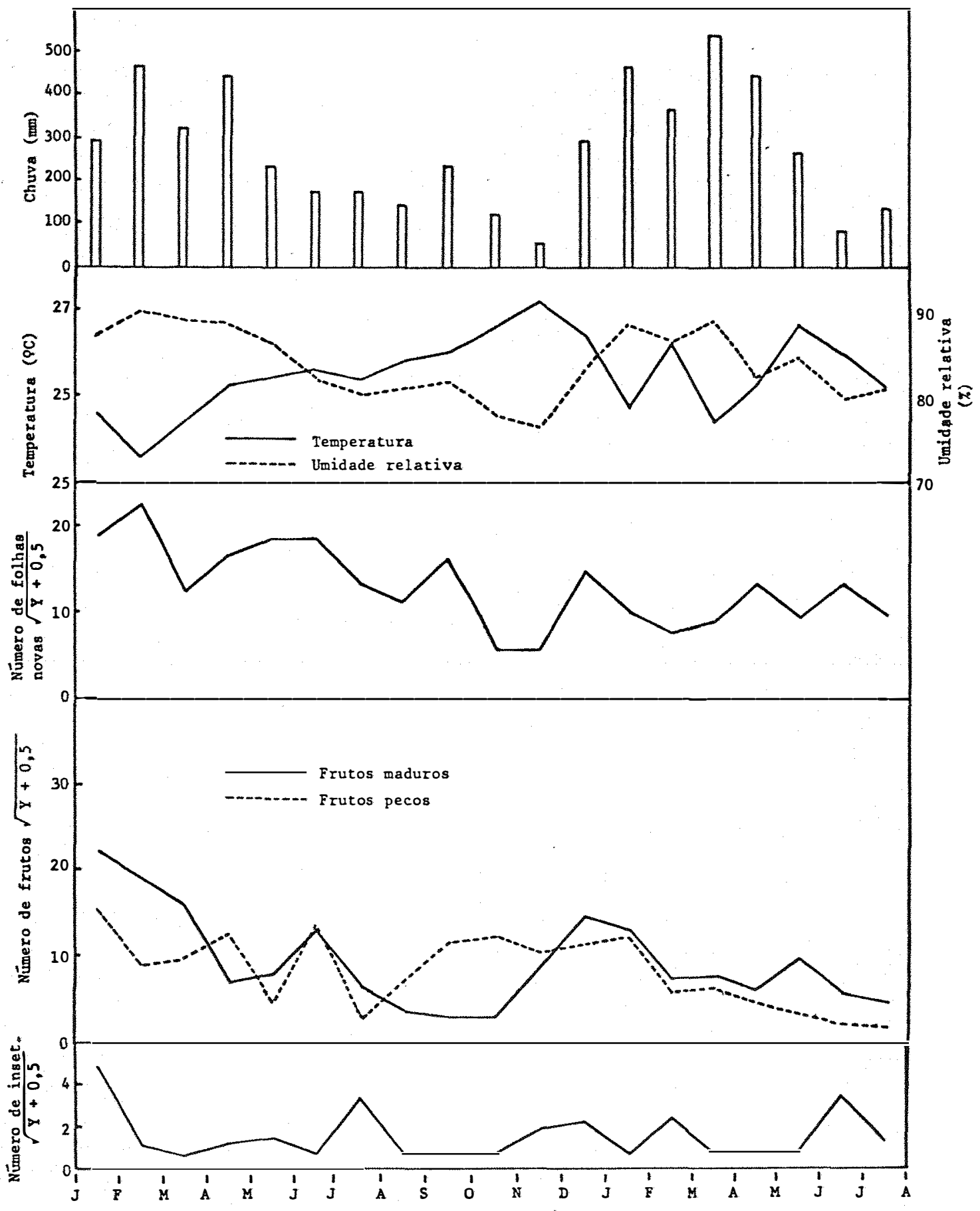

Fig. 8 - Flutuaçāo populacional de costalimaita ferruginea ell confronto com os fatores climáticos e fenológicos do cacaueiro na Regiāo Bragantina (Pa) 


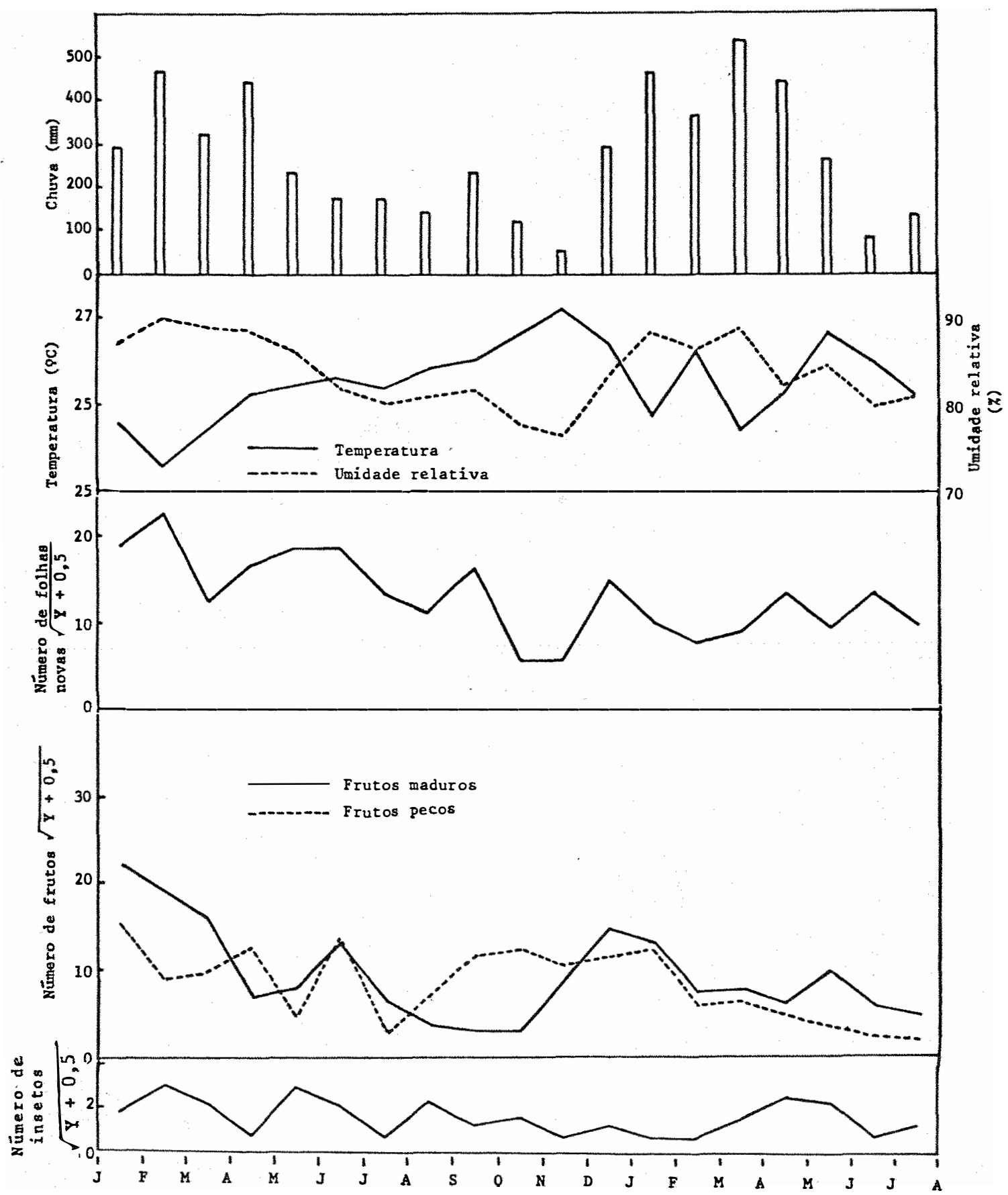

Fis. 9 - Flutuação populacional de Ephyraea sp. em confronto coll os fatores climáticos e fenológicos do cacaueiro na Regiāo Bragantina (Pa) 


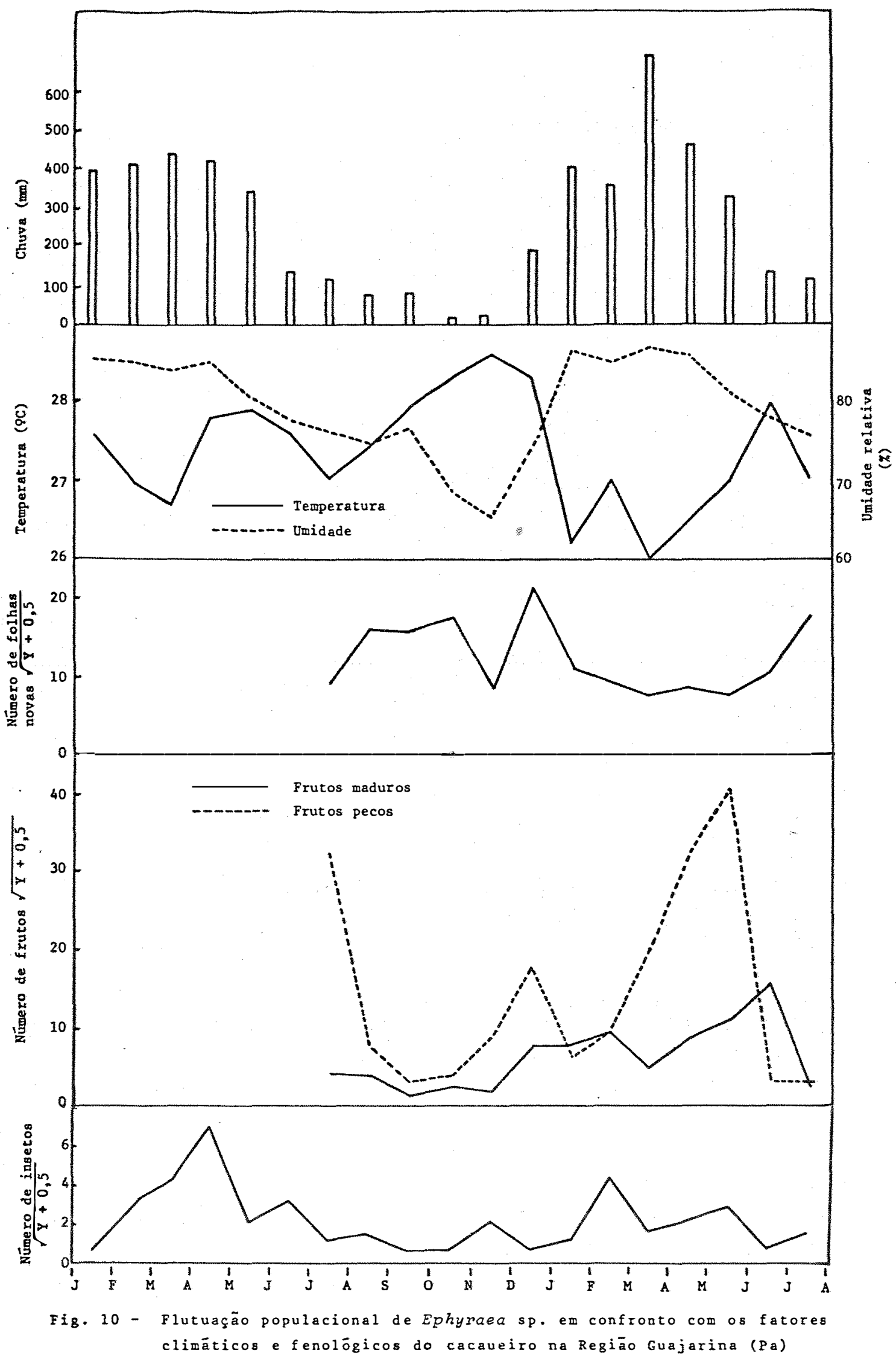




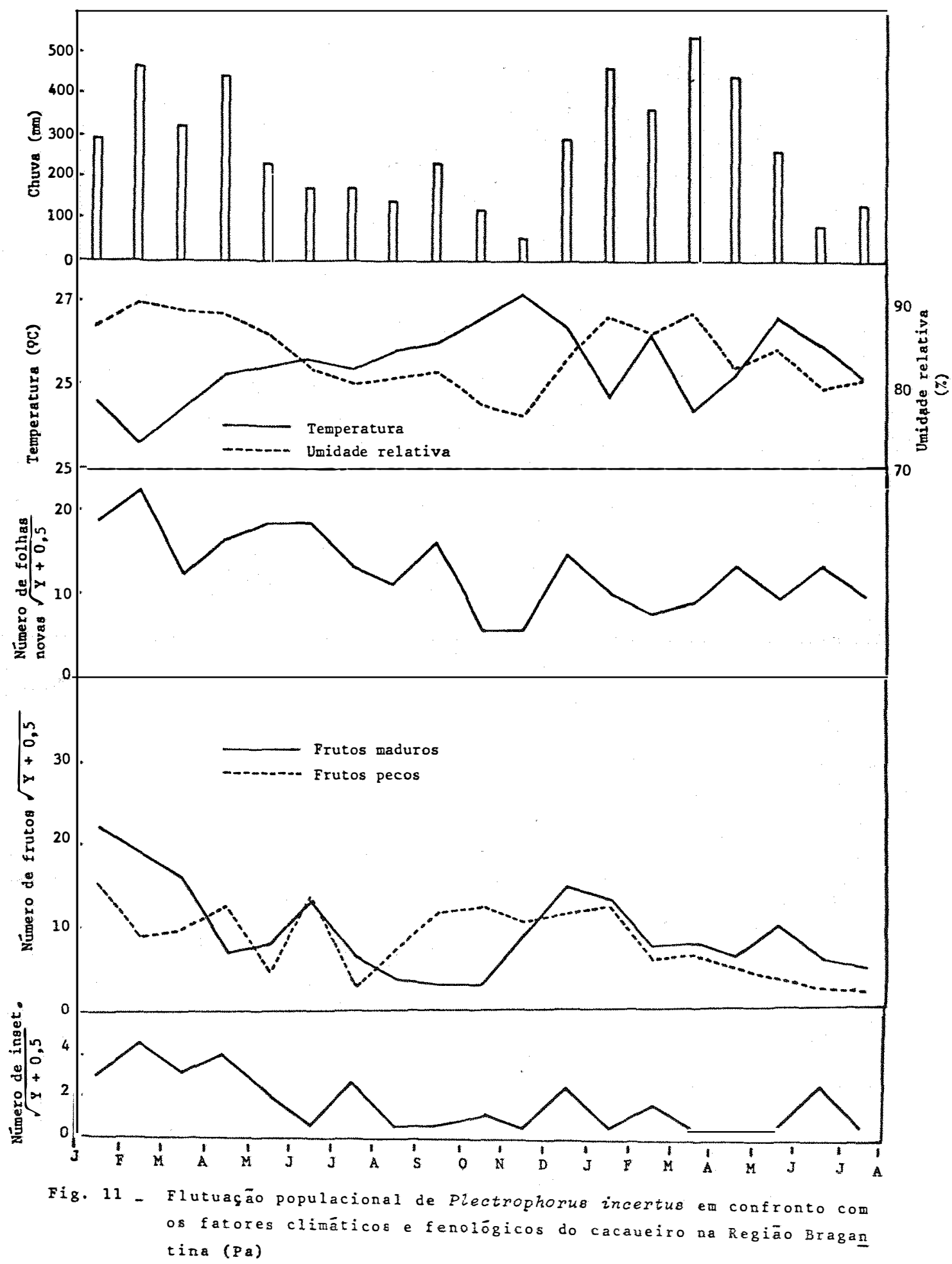




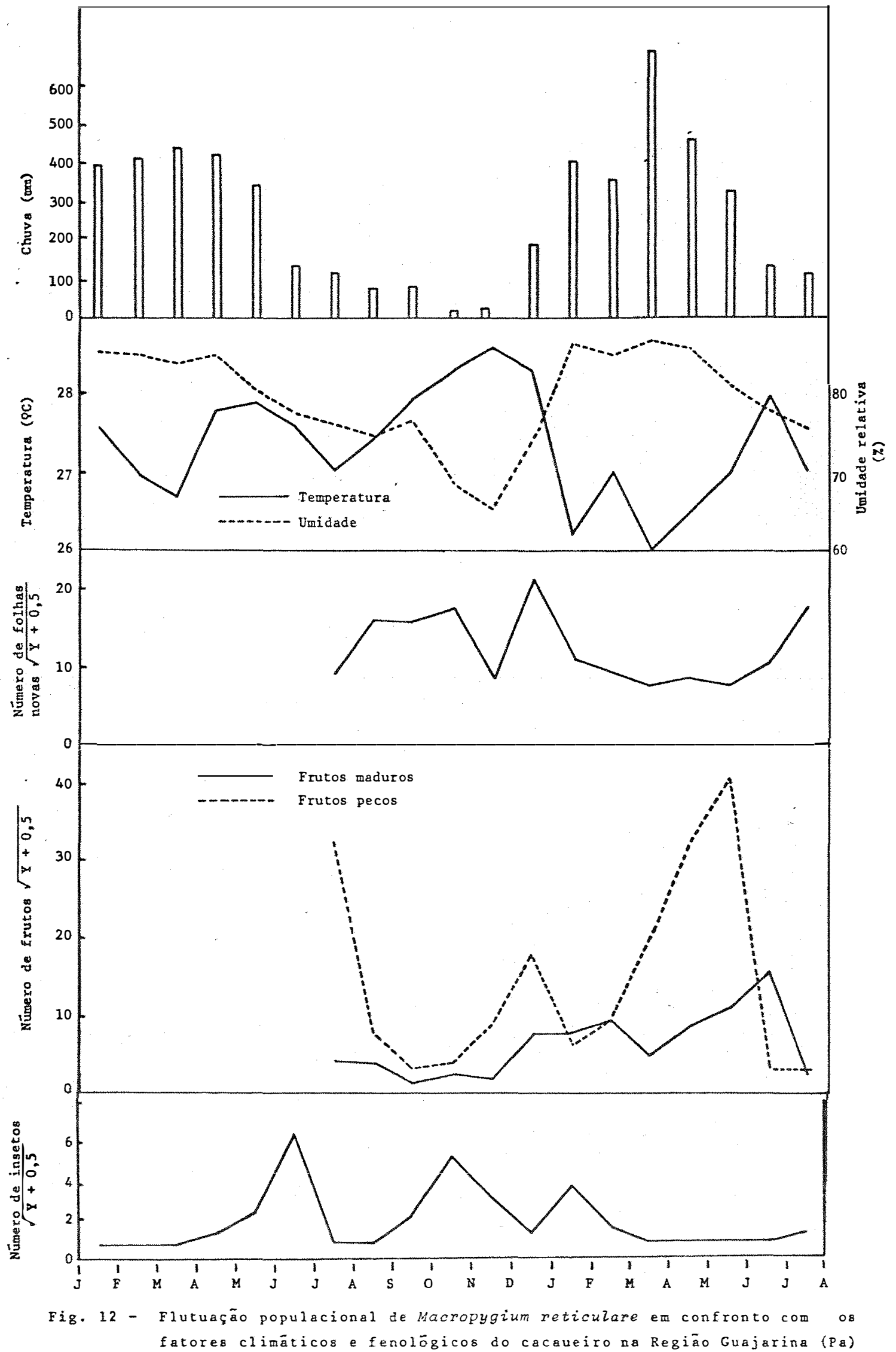




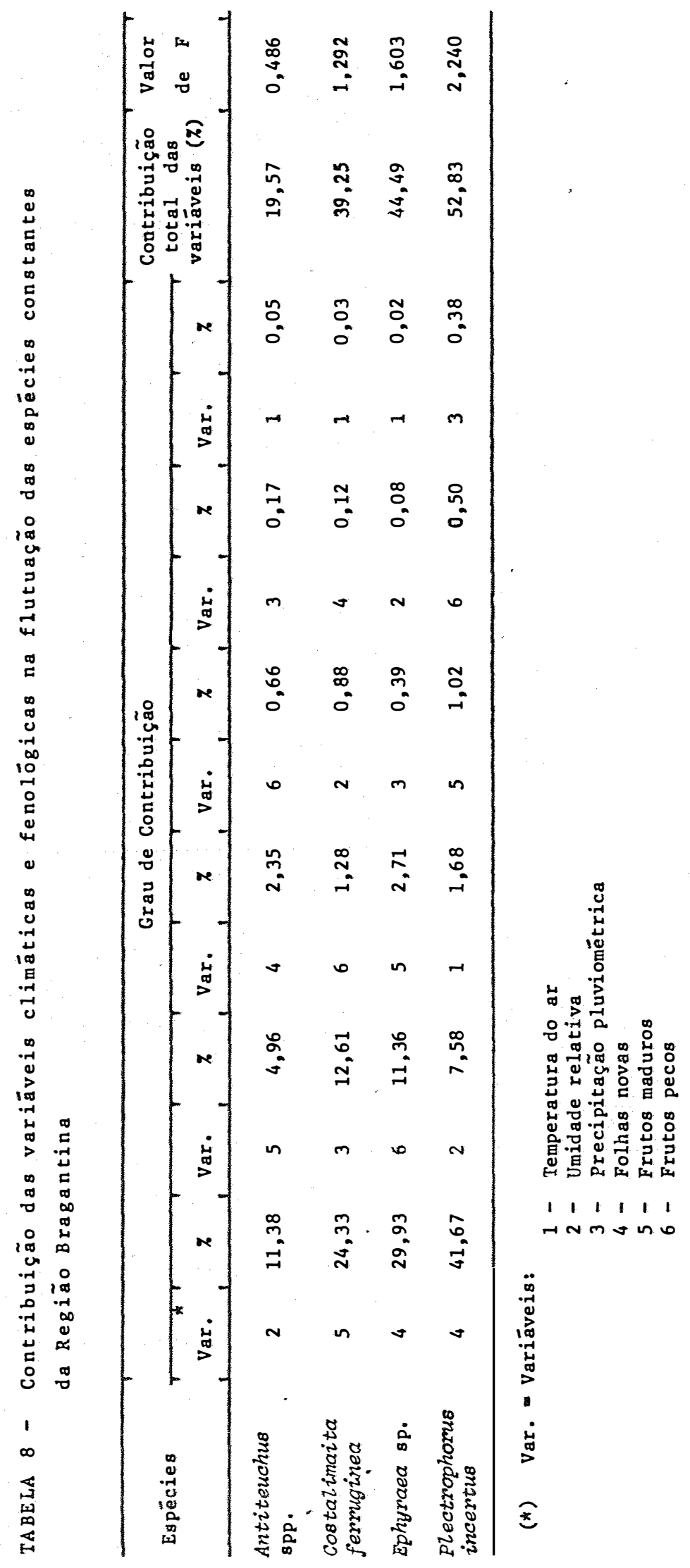




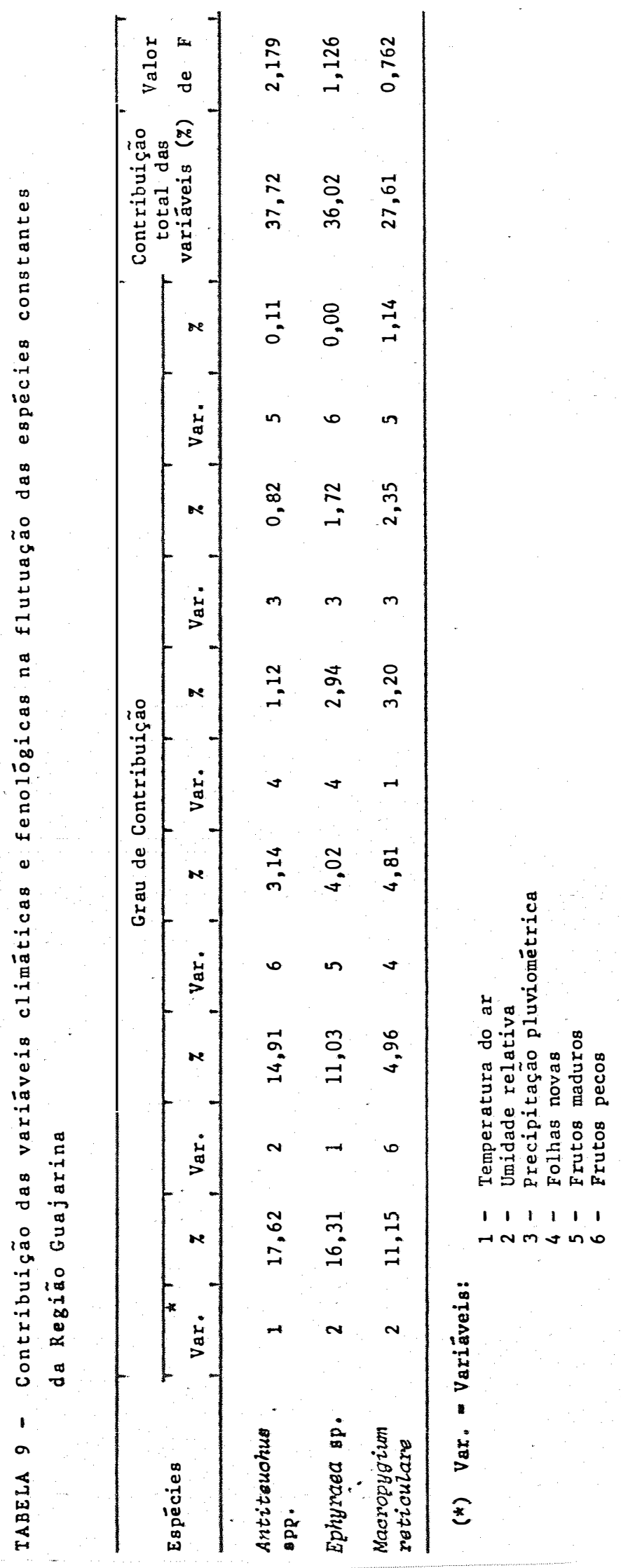


A anālise da flutuação de cada espécie revelou:

\section{Antiteuchus spp.:}

As espécies deste gênero, na Região Bragantinasapre sentaram uma flutuação com um pico bastante expressivo durante o mês de novembro, conforme mostra a Figura 6 . 0 pico po pulacional coincidiu com a menor precipitação pluviométrica, umidade relativa mais baixa e temperatura alta. Durante os outros meses, a distribuição da população destas espécies não mostrou nenhuma correlação com os fatores climáticos. Com a fenologia do cacaueiro, observa-se também, pela Figura 6 , que não houve correlação que pudesse sugerir qualquer influência destes fatores na flutuação dos insetos.

De acordo com a anāilse de regressão, dentre as variáveis estudadas a que apresentou maior influência foi a umi dade relativa do ar, com uma contribuição de $11,38 \%$, conforme mostra a Tabela 8 . 0 conjunto das variáveis independentes, teve uma influência na flutuação de apenas $19,57 \%$, cujo valor de $F$ para a regressão mültipla, não foi significativo.

Na Região Guajarina, o comportamento da população destas espëcies, mostrou dois picos durante o período, observando-se que, ao contrário da Região Bragantina, esses picos coincidiram com as maiores chuvas, umidades elevadas e temperaturas mais baixas, conforme está evidenciado na

Os fatores fenológicos mais uma vez não mostraram nenhuma con 
relação com a flutuação destas espécies.

De acordo com a análise de regressão, a temperatura do ar e a umidade relativa, foram as variáveis que mais contribuiram na flutuação destas espécies, dentro da Região Guajarina, $\operatorname{com} 17,62 \%$ e $14,91 \%$, respectivamente. As variáveis em conjunto, influiram em $37,72 \%$, sendo F não significativo (Tabe1a 9).

Fica demonstrado portanto que, tanto na Região Bragantiaa quanto na Guajarina,outros fatores não evidenciados no estudo, estão influindo na flutuação das espécies, em $80,43 \%$ e $62,28 \%$, respectivamente.

Costalimaita ferruginea Fabr., 1801

A flutuação desta espēcie na Região Bragantina, foi bem distribuída durante o período, não mostrando nenhuma correlação com os fatores climáticos e fenológicos do cacaueiro, conforme pode ser observado na Figura 8 .

A anālise de regressão mültipla, mostrou que os fru tos maduros, foi, entre as variáveis estudadas, o fator que mais contribuiu para explicar o evento, com uma contribuição de $24,33 \%$. As variáveis em conjunto, tiveram uma participação de $39,25 \%$, entretanto o valor de F não foi significativo. Oucros fatores influiram na flutuação em $60,75 \%$ 。 


\section{Ephyraea sp.:}

A distribuição populacional desta espécie, apresentou-se tambēm bastante equilibrada na Região Bragantina, não sugerindo nenhuma correlação com os fatores climäticos e feno lögicos, como se pode observar pela Figura 9.

os resultados da anālise de regressão mültipla, como evidencia a Tabela 8 , mostram a variável folhas novas, co mo a mais importante, com uma contribuição de $29,93 \%$. As variāveis em conjunto influiram em $44,49 \%$ mas o valor de $F$ não foi significativo.

Na Região Guajarina esta espēcie apresentou um pico mais evidenciado no mês de abril de 1977 e um outro menor em fevereiro de 1978 , sugerindo assim, uma correlaça ão positiva com chuva e umidade relativa e negativa com a temperatura.

Com os fatores fenológicos não foi possível estabelecer compa rações pela falta de dados no início do período (Figura 10).

A anālise de regressão mostrou a umidade relativa como a variável mais importante com $16,31 \%$ e a temperatura com 11,03\% de contribuição. O conjunto das variāveis contribuiu com $36,02 \%$, sendo o valor de F não significativo.

Outros fatores não analisados, influiram em 55,51\% e $63,98 \%$ respectivamente, nas Regiões Bragantina e Guajarina, conforme deduz-se pelas Tabelas 8 e 9 . 
Plectrophorus incertus voss

Esta espécie foi constante somente na Região Bragan tina e ocorreu em maior intensidade de janeiro a abril de 1977, mostrando, de acordo com a Figura 11, uma correlação positiva com as folhas novas do cacaueiro.

A anālise de regressão múltipla confirmou essa observação, notando-se através da Tabela 8 , uma contribuição de $41,67 \%$ da variāvel na flutuação dessa espécie. As variāveis em conjunto influiram em $52,83 \%$, entretanto o valor de F não foi significativo, porquanto outros fatores ainda influiram em $47,17 \%$. As observações de SILVA e CoSTA (1973), ao mencionarem a presença desta espécie causando danos às foThas do cacaueiro, em Belém, foram assim, confirmadas, levando-se a acreditar que este inseto poderá constituir-se numa praga de grande importância econômica para a cacauicultura da região.

\section{Macropygium reticulare (Fabr., 1803)}

Esta espécie foi constante somente na Região Guajarina e teve a sua maior densidade populacional distribuída no período de junho a janeiro, com dois picos característicos, sendo um em junho e outro em outubro. A Figura 12 sugere por tanto que a baixa umidade relativa, pouca chuva e temperatura elevada, sejam fatores ideais para o seu desenvolvimento. 
A anālise de correlação mültipla, mostrou a umidade relativa, como a variável mais importante, com $11,15 \%$ de contribuição, conforme mostra a Tabela 9 . 0 grau de contribuição das variáveis em conjunto, foi de $27,61 \%$, cujo valor de F não foi significativo. Outros fatores estão contribuindo para o evento em $72,39 \%$.

Já está bastante estudada e suficientemente comprovada a correlação existente entre os fatores climáticos com a intensidade de lançamentos de folhas novas no cacaueiro, con forme trabalhos de SALE (1968), ALVIM et alii (1969), etc. Muitos trabalhos, como o de ABREU (1971), também jā demonstra ram a dependência da população de insetos filófagos com a flu tuação periódica dos lançamentos de folhas novas do cacaueiro. Na Amazônia ou mais precisamente no Estado do Pará, estas cor relações ainda não estão perfeitamente esclarecidas. Com relação ao clima, observa-se apenas uma ligeira tendência na in fluência destes fatores sobre os lançamentos de folhas novas do cacaueiro. No que diz respeito a dependência da flutuação populacional deste grupo de insetos com a fenologia do cacaueiro, pouco se pode concluir. Em alguns exemplos isolados co mo o do Ephyraea sp. e do Plectrophorus incertus na Região Bragantina, ficou evidenciada esta correlação, entretanto com um grau de contribuição muito baixo da variável sobre estes insetos. 
Com relação aos insetos do grupo dos sugadores, os fatores estudados não mostraram tambēm qualquer influência marcante na flutuação dos mesmos. Os percentuais de contribuição de temperatura e umidade relativa na flutuação de Anti teuchus spp. e Macropygium reticulare, são considerados mui to baixos para explicar o evento.

Os resultados sugerem portanto, que a flutuação populacional das espécies estudadas, ainda não está inteiramente dependente da fenologia do cacaueiro, supondo-se todavia, que a influência maior esteja relacionada com outros fatores presentes, tais como a existência de outras culturas próximas como fonte principal de alimentação desas espécies.

Com a expansão das āreas cacaueiras nas regiões estudadas, possivelmente os häbitos alimentares e o comportamen to de muitas espécies venham a ser modificados em função de um novo nicho ecológico formado, estabelecendo-se assim a ve dadeira entomofauna do cacaueiro na Amazônia, provavelmente diferindo daquela $\mathrm{ja}$ preconizada para as áreas cacaueiras da Bahia e Espirito Santo, conforme BONDAR (1939), ABREU (1963) e ABREU e SILVA (1972). 
6 - CONCLUSÖES

Do presente trabalho podem ser tiradas as seguintes conclusões :

a - Na Região Bragantina foram coletados 840 individuos distribuídos entre 8 familias e 46 espécies.

b - Na Região Guajarina foram coletados 695 individuos dis tribuídos entre 6 familias e 36 espécies.

c - A fauna da Região Bragantina é mais numerosa e diversificada que a fauna da Região Guajarina.

d - A Região Bragantina apresenta 3 espécies constantes, 4 acessörias e 39 acidentais. 
e - A Região Guajarina apresenta 2 espécies constantes, 3 acessōrias e 31 acidentais.

f - A espécie mais frequente da Região Bragantina é o Antiteuchus sepulcralis e da Região Guajarina $\vec{e}$ o Ephyraea sp.

$g$ - 0 quociente de similaridade entre as duas regiões é de $58,5 \%$

h - No estudo da flutuação populacional de Antiteuchus spp., Costalimaita ferruginea, Ephyraea sp. e Plectropho rus incertus da Região Bragantina e Antiteuchus spp., Ephyraea sp. e Macropygium reticulare da Região Guajarina, não houve correlação significativa com os fatores climáticos e fenolögicos do cacaueiro. 
7 - SUMMARY

This research was carried out in order to identify the insects Orders Coleoptera Hemiptera associated with cocoa tree in the state of Para, Brazil. The main goals of the study were to study the faunistic indexes and to correla te the population curves of the constant species with the meteorological factores and the phenological factors of the cocoa tree.

The surveys were done monthly by using the knockdown method with $12 \%$ B.H.C. in the regions of Bragantina and Guajarinas from January 1977 to July 1978.

The results were as follows: 
In the Bragantina region 840 specimens were collected ( 8 families and 46 species), while in the Guajarina region 695 specimens were collected ( 6 families and 36 species). From the species of the Bragantina region 3 are cons tants, 4 accessiries and 39 accidentals, while from those of the Guajarina region 2 are constants, 3 accessories and 31 accidentals.

Antiteuchus sepulcarlis (Fabr., 1803) (Hemiptera Pentatomidae) is the most frequent species in the Bragantina region and Ephyraea sp. (Coleoptera - Chrysomelidae) frequent one in the Guajarina region.

The quotient of similarity between those two regions is $58.5 \%$.

The study of the population fluctuation of the cons tant species indicated no significant correlation with the me teorological factors and the phenological factors of the cocoa tree. 
ABREU, J. M., 1968. Problemas entomológicos da cacauicultura no Espirito Santo. Turrialba. Costa Rica, 18(2): 182-186.

ABREU, J. M., 1971. Fenologia de alguns coleöpteros nocivos ao cacaueiro no Espírito Santo. Piracicaba. ESALQ/USP, 54 p. (Dissertąão de Mestrado).

ABREU, J. M. e P. SILVA, 1972. Pragas potenciais do cacauei ro na Bahia e no Espirito Santo. Cacau Atualidades, Ita buna, $9(3): 4-9$.

ÁLVARES-AFONSO, F. M., 1975. Os polos cacaueiros da Amazó nia. (S. 1.) CEPLAC, 14 p. (datilografado). 
AlviM, P. de T., 1969. Alguns estudos sobre as relaçöes de água, solo e crescimento do cacaueiro. In: Memórias da Segunda Conferência Internacional de Pesquisas em Cacau. Salvador e Itabuna, Bahia. 19-26 de novembro de 1967, PP. 316-324.

BONDAR, G., 192\%. O Cacao. Parte I - A Cultura e Preparo de Cacao. Bahia, Brasil, $118 \mathrm{p}$.

BONDAR, G., 1936. Insetos da familia dos otiorhynchídeos no civos ao cacaueiro. Chácaras e Quintais, 54(6) 752-753.

BONDAR, G., 1939. Insetos nocivos ao cacaueiro. Instituto de Cacau da Bahia. Boletim Técnico n? 5. $112 \mathrm{p}$.

BRUNEAU DE MIRE, Ph., 1971. Observations sur les fluctua tions saisonnières d'une population de Sahlbergelza singu laris au Cameroun. In: Conference Internationale sur les Recherches Cacaoyeres, $3^{a}$, Accra, Ghana, 1969. Cocoa Research Institute. PP. 242-243.

CALDEIRA, E. S. e J. T. VIEIRA, 1938. Primeiro catálogo dos insetos que vivem nas plantas do Estado do Parä. Diretoria Geral da Agricultura e Pecuária do Estado do Para, Be $1 \overline{\mathrm{e}} \mathrm{m}, 17 \mathrm{p}$.

CALLAN, E. McC., 1943. Natural enemies of the cacao thrips. Bu11. Ent. Res., 34: 313-321.

CONDURU, J. M. P., 1966. Culturas principais da Amazônia. Serviço de Informação Agrícola. Ministério da Agricultura, Rio de Janeiro, Brasil, pp. 13-14. 
CostA IIMA, A. M. da, 1949. Lepidópteros. In: Insetos do Brasil. Rio de Janeiro, E.N.A., Vol.6, pt. 2 (série didática 8).

Costa LIMA, A. M. da, 1953. Coleópteros. In: Insetos do Brasil. Rio de Janeiro, E.N.A., Vol.8, pt. 2 (série didática 10).

CostA LIMA, A. M. da, 1955. Coleópteros. In: Insetos do Brasil. Rio de Janeiro, E.N.A., Vol. 9 , pt. 3 (série didätica 11).

CostA LIMA, A. M. da, 1956. Coleópteros. In: Insetos do Brasil. Rio de Janeiro, E.N.A., Vol. 10 , pt. 4 (série didática 12).

D'ARAúJo e Silva, A. G. ; C. R. GONÇAlves; D. M. Galvão; A. J. L. GONÇALVES; J. GOMES;M. do N. SILVA e L. de SIMONI, 1968. Quarto Catálogo dos Insetos que Vivem nas Plan tas do Brasil. Rio de Janeiro, Ministério da Agricultu= ra. $906 \mathrm{p}$.

DRAPER, N. R. e H. SMITH, 1966. Applied regression analysis . John Wiley e Sons, Inc., New York, 407 p.

EGUAGE, W. E., 1977. Distribution and seasonaly in relation to chemical control of Sahbergelza singularis Haglund Heteroptera; Miridae in Nigeria. In: Conference Internationale sur les Recherches Cacaoyeres, $5^{a}$, Ibadan, Nigéria, 1975. Procedimento. Ibadan, Nigéria, Cocoa Re search Institute. pp. 465-481. 
ENTWISTLE, P. F., 1964. Cocoa mirids in Nigeria: a riview of present know-ledge. In: Procedings of Cacao Mirid Control Conference, Tafo, Ghana, $6^{\text {th }}$ and $7^{\text {th }}$ August, 1963. Pp. 55-61.

FENNAH, R. G., 1954. The epidemiology of cacao-thrips on cacao in Trinidad. In: Imperial College of Tropical griculture. A Report on Cacao Research, 1954. Trini dad. Pp. 7-26.

KOPPEN, W., 1948. Climatologia. Traduzido da $2^{a}$ edição em alemão, por P. R. Perez, Buenos Aires, F.C.E. 478 p.

LAVABRE, E. M. ; J. DECELLE e P. DEBORD, 1962. Recherches sur les variations des populations de Mirides (capsides) en Côte D'Ivoire. Café Cacao Thé, 6

LAVABRE, E. M. ; J. DECELlE e P. DEBORD, 1963. Etude de l'évolution régionale et sajoniere des populations de merides (capsides) em Côte D'Ivoire. Café Cacao Thé , 근 3 : 267-289.

MORALES, M. E. ; A. A. MATARRITA; P. O. VARGAS; M. I. SOLIS; M. R. MURILLO e P. R. VAN-DYCK, 1963. Flutuaciones de algunas poblaciones insectiles del cacao en el Atlantico. Ministerio de Agricultura y Ganadeira, Costa Rica. Boletim Técnicone 45, 19 p.

NASCIMENTO, J. C. ; A. MOREIRA FILHO;A. M. de C. GOMES e M. R. de A. JUNQUEIRA, 1975. Situação atual do cultivo do cacau no Amazonas. Cacau atualidades. CEPLAC, Km 22 da Rodovia Ilhéus-Itabuna. Ilhêus, Bahia, Brasil, $12(4):-1,3-16$ 
PRICE, P. W. e G. P. WALDBAUER, 1975. Ecological Aspects of Pest Management. In: Introduction to Insect Pest Mana gement. New York, John Wiley \& Sons.pp. 37-74.

REYNE, A., 1921. De Cacaothrips (Heliothrips rubrocinctus Giard). Department Van Den Landbouw in Suriname. Bull. no 44, 214 p.

SALE, P. J. M., 1968. Flushing and leaf growth of cacao under controlled temperature conditions. Journal of Horticultural science, 43: 475-489.

SEFER, E., 1961. Catálogo dos insetos que atacam as plantas cultivadas da Amazônia. Boletim Técnico do Instituto Agronômico do Norte. Belém, 43: 23-53.

SILVA, L. F. da; F. M. ALVARES-AFONSO e A. C. P. DIAS, 1976. Disponibilidad de suelos para cacao en la Amazonia brasi1eña. Revista Theobroma. Ilhēus, Brasil, 6(31): 31-39.

SILVA, P., 1944. Insect Pests of Cacao in the State of Bahia, Brasil. Tropical Agriculture, 21 (1): 8-14.

SILVA, P., 1957. Problemas entomológicos do cacaueiro com referência especial à Bahia. In: VI Reunião do Comitê Técnico Interamericano de Cacau. 20 a 27 de maio de 1956 , Bahia, Brasil. pp. 59-72.

SILVA, P. e A. da S. COSTA, 1973. Novas pragas do cacaueiro no Brasil. Revista Theobroma. CEPEC, Itabuna, Brasil, 3(1): $\quad 42-43$. 
Silva, P. ; J.A. VENTOCILla ; G. E. SMITH e J. M. de ABREU, 1969. Estudos recentes sobre a entomologia do cacaueiro na Bahia e Espirito Santo. In: Memórias da Segunda Conferência Internacional de Pesquisas em Cacau, 19 a 26 de novembro de 1967, Salvador/Itabuna, Bahia, Brasil. PP. 253-258.

SILVEIRA NETO, S.; O, NAKANO; D. BARBIN e N. A. VILlA NOVA, 1976. Manual de Ecologia dos Insetos. São Paulo, Edito ra Agronômica Ceres. 419 p.

SMITH, F. G. E., 1972. Principais pragas do cacaueiro no Es tado do Espírito Santo, Brasil. Cacau atualidades, 9(1): $22-27$.

SMITHs F. G. E., 1973. Dinâmica populacional do Selenothrips rubrocinctus (Giard, 1901) (Thysanoptera : Thripidae), na Região Cacaueira do Espírito Santo, Brasil. Piracicaba, ESALQ/USP, 65 p. (Dissertação de Mestrado).

SMITH, F. G. E. e J. A. VENTOCILlA, 1971. Indice de estra gos causados pelo Selenothrips rubrocinctus (Giard) em folhas e frutos do cacaueiro. Informe Técnico 1968/1969. Centro de Pesquisas do Cacau, Itabuna, Bahia, Brasil. $208 \mathrm{p}$.

SORENSEN, T., 1948. A method of establishing groups of equal amplitude in plant sociology basead an similarity of species. Biol. Skx., 5: 1-34.

SOUTHWOOD, T. R. E., 1971. Ecological Methods. Champman and Hall Ltda., $391 \mathrm{p}$. 
TEYLOR, D. J., 1955. Capsid Research: population studies.

In: West African Cocoa Research Institute Report. 1954/ 1955. pp. 61-63.

URICH, W. F., 1911. The cacao Thrips (Heliothrips rubrocinctus Giard). Board of Agr. Trinidad, 12: 3-10.

VENTOCILla, J.A., 1967. Flutuação da população de insetos em cacauais no CEPEC (Luz negra). In: Informe Técnico. 1967. CEPEC-CEPLAC, Itabuna, Bahia. pp. 60-61.

VENTOCILla, J.A., 1970. Flutuação de população de insetos em cacauais do CEPEC (Luz negra). In: Informe Técnico. 1969. CEPEC-CEPLAC, Itabuna, Bahia. 208 p.

VENTOCILLA, J.A., 1975. Relatório de viagem ao Territōrio Federal de Rondônia - Nücleo Colonial do Incra. Dizol, CEPEC, Itabuna, 3 p. (Datilografado).

VILLACORTA, A., 1977. Fluctuacion Anual de la Poblaciones de Monalonion annulipes Sig. y su Relacion com la "Muerte Descendente de Theobroma cacao" em Costa Rica. In: Anais da Sociedade Entomolögica do Brasil, 6(2): 215223 .

YOUDEOWEI, A., 1969. Studies on the timing of insecticides application to control the capsid, Sahlbergelza singularis Hagl. on cacao in Nigeria: The effect of spraying in april and may when the capsid population is low. In: Documentos Apresentados na III Conferência Internacional de Pesquisas em Cacao, Accra, Ghana, 23 a 29 de novem bro. (Mimeografado). 
WILLIAMS, G., 1954. Field observations on the cacao mirids Sahlbergella singularis Hagl and Distantiella theobro mae (Dist.), in the Gold Coast. Part III: Population Eluctuations. Bulletin of Entomological Research, 45: 723-744. 